Mukaddime, 2020, 11(2), s. 410-445.

DOI: 10.19059/mukaddime.732473

\title{
Di Devokên Kurdîya Kurmancî de Zayenda Rewşên Morfolojîk (Mînakên Devokên Bakur, Bașûrê Rojhilat û Başûrê Rojavayê)
}

Mehmet YONAT

\section{Kurmanci Kürtçesi Ağızlarının Hal Eklerinde Cinsiyet (Kuzey, Güneydoğu ve Güneybatı Ağızları Örnekleri)}

Öz

Kurmanci Kürtçesi gramatik cinsiyete sahip bir dildir. İsimlerin cinsiyeti isimler yalın halde iken ve isimler yalnız başına kullanıldığında anlaşılmaz. İsimlerin cinsiyetinin anlaşılabilmesi için, isimlerin ya bükümlü ya da seslenme/ünlem hallerinde kullanılması gerekir. Keza, izafe yapısı içerisinde izafe partikeli isimlerin cinsiyetini gösterir. Kurmanci Kürtçesi bir çok ağıza sahiptir ve cinsiyet eklerinin kullanımı bazı ağızlarda ortadan kalkmakla birlikte bazı ağızlarda ise form değiştirmektedir. Bu çalışmada Kurmanci Kürtçesinin üç ağzının hal eklerindeki cinsiyet kullanımı ayrıntılı bir şekilde analiz edilmiştir. Seçilen bu ağızlar; güney doğu, kuzey ve güney batı ağızlarıdır. Bu sınıflandırma Kurmanci ağızları üzerine yapılan en son çalışmalara göre yapılmış olup aşağıda ayrıntılarıyla verilecektir. Güney doğu ağzı için Şırnak ili Beytüşşebab ilçesinin bir köyü; güney batı ağzı için Adıyaman merkez ilçesi ve kuzey ağzı için ise Muş merkez ilçesinin bir köyü seçilmiştir. Bu ağızların analizi için bu makalenin yazarı tarafından bir ölçüm aracı geliştirilmiştir. Bahsi geçen ölçüm aracı elli beş sorudan oluşmaktadır. Bu sorular konuşmacılara Türkçe sorulup cevapları Kürtçe alınmıştır. Kürtçe hızlı bir değişim (ya da asimilasyon) içinde olduğundan dolayı, bir bölgenin konuşurları yaşları ve cinsiyetleri bağlamında aynı gramatik form için farklı kalıplar kullanabilmektedirler. Bundan dolayı, konuşucular yaş; yaşlı, ortayaşlı, genç ve cinsiyet; kadın ve erkek olacak şekilde bir ayrıma tabi tutulmuşlardır. Bu çalışmada elde edilenler şu şekilde özetlenebilir; her ne kadar güney doğu ve güney batı ağızlarında hemen hemen standart Kurmanci ile aynı kullanım var olsa da, kuzey ağzında belirsiz çekimlerde ve işaret sıfatları ve zamirleri çekimlerinde cinsiyete karşı hassasiyetin tamamen ortadan kalktığı görülmüştür. Yine, belirli isimlerin spesifik olmayan çekimleri Türkçenin etkisinden dolayı normalde büküm ekleri alması gerekirken bu ekleri almamıştır. Son olarak şu söylenebilir; tüm

1 Arş. Gör. Dr., Mardin Artuklu Üniversitesi, Yaşayan Diller Enstitüsü Kürt Dili ve Kültürü Anabilim Dalı, mehmetyonat49@gmail.com, ORCID ID: 0000-0001-8576-7486. 
ağızlarda genç konuşmacılar yaşlı konuşmacılara nispeten gramatik cinsiyet uyumuna karşı daha az hassasiyet göstermişlerdir.

Anahtar Kelimeler: Kurmanci Kürtçesi, Cinsiyet, Ağız, Büküm, Seslenme Durumu, Belirlilik, Belirsizlik.

\title{
Usage of Gramatical Gender of Morphological Cases in Kurmanji (the Examples of North, Southeast and Southwest Varieties)
}

\begin{abstract}
Kurmanji Kurdish have grammatical gender. When nouns are in the direct case or used solely it is not possible to understand nouns gender. In order to understand the gender of nouns, nouns have to used in the oblique or vocative cases. Moreover, the ezafe structure is a grammatical structure in which the gender of nouns could be able to figure out. Kurmanji Kurdish have various accents. The form of gender suffixes or particles could show different characteristics. Some accents even lost some gender agreement forms completely.

In this study, three of Kurmanji Kurdish accents were analyzed in terms of gender in case. The accents are Northern, South-Eastern, and SouthWestern accents. Kurdish Kurmanji accents have been classified according to up-to-date studies (Haig and Öpengin, 2014). For South-Western accent one village of Şırnak Province; for South-Western accent center of Adiyaman Province; and for Northern accent one village of Mus Province selected. To be able to analyze the accent's gender usage a measurement tool has been developed by the writer of the article. The measurement tool consists of fifty-five questions. The questions asked to interviewers in Turkish and they responded to them in Kurmanji Kurdish. Due to the resent transformation or assimilation of Kurdish, the interviewers may use some different forms. That is why the interviewers classified by their gender; male and female, and their age; young, middle-aged, and old. What are drow out from this study is that; even though the usage of gender in the grammatical cases like standard Kurdish Kurmanji in the South-Western and South-Eastern accent, in the northern accent the indefinite gender suffixes and the determiners lost their gender agreement. Again in the northern accent, because of Turkish influence on Kurmanji Kurdish, in the nonspecific-definite situation, the oblique singular case suffixes do not use. Lastly, it could be said that the young interviewers are less sensitive to gender agreement than old ones.
\end{abstract}

Keywords: Kurmanji Kurdish, Gender, Accent, Oblique Case, Vocative Case.

\section{Extended Abstract}

Gender is an important factor in human life. That is why it affects a wide range areas of life. Language is an area on which biological gender has been shown. Some language show biological gender just in lexical domain 
while others exhibite biological gender both lexically and gramtically. Kurdish (Kurmancji) is a language which has gramatical gender. The gender of nouns can not be understand when they are in direct case or used solely. To be able to understand the gender of nouns, nouns sould be inflected either in oblique case and vocative case, or in ezafe construction. In this study, three varieties of Northern Kurdish have been analyzed in terms of gender of morphological cases. As mentioned above oblique and vocative cases are the morphological cases where gramatical gender has been seen on. In vocative case, gender of nouns has a quite simple system; male anmimate nouns take $\{-0\}$ suffix and female ones inflect with $\{-\hat{e}\}$ suffix. The plural infelction has no gender distinction and takes $\{-(i) n o\}$ suffix. The relatively complex case in terms of gender agreement is oblique case in which there are definitive, indefinitive and demonstrative inflection of nouns. In the definitive infelction, the male nouns take $\{-\hat{i}\}$ suffix and female nouns take $\{-\hat{e}\}$ suffix. The indefintive form firstly takes indefinitive suffix $\{-\mathrm{ek}-\}$ and then same suffixes used for definitive form follow it. Lastly, the demonstrative form consists of demonstrative adjectives and demonstrative pronouns which differ in accordance with gender and distantness of the main noun which is used in definitive form. Like vocative case, in oblique case plural inflection does not have gender distinction.

The varieties of Northern Kurdish which are selected for this article are South-eastern variety, Northern variety and South-western variety. This clasification has been made according to the latest studies which is about Kurmanji Kurdish varieties. In order to analyse different usage of gramatical gender of morphological cases among the selected varieties, a measurement tool has been developed by the writer of this article. The measurement tool consists of fifty five questions which aim to clarify all of form of oblique and vocative case usages. The questions asked to interviewees in Turkish and the answers recieved in Northern Kurdish. Becasuse of fast-paced transformation (or assimilation) of Northern Kurdish, it is possible that the different interviewees employ different grammatical usages for same grammatical pattern. That is why the interviewees have been divided by age; old, middle-aged and young; and sex; male and female. For finding of the study, even though South-eastern and South-western varieties show nearly identical features of standart Northern Kurdish, the Northern variety has lost sensitivity to gramatical gender in the oblique inflection of indefinitives and demonstratives. As mentioned above, in the indefinitive infelction of oblique case, $\{-\mathrm{ek}-\}+\{-\hat{\}}\}$ suffixes follow male nouns, like "kurik-ek-î" (a boy) and $\{$-ek-\} $+\{-\hat{e}\}$ suffixes pursue female nouns, like "keçik-ek-ê". In addition to that, demonstrative adjectives have gender agreement with main nouns. Male forms of demonstrative adjectives "vî (porximate.male), wî (distal.male)" agree with male nouns, like "vî/wî kurik-î" (this/that.Oblique.Male boy.Oblique.Male) and female forms of demonstratives "vê (porximate.female), wê (distal.female)" agree with female nouns, like "vê/wê keçik-ê" (this/that.Oblique.Female girl.Oblique.Female), and main nouns of the phrases assign like definitive agreement. Yet, it is not the case for Northern variety of Kurmanji Kurdish. In the indefinitive inflections of this variety, the gender distinction has disapeared in fovor of 
male agreement, like "kurik-ek-1”" (a boy) and "keçik-ek-î"(a girl). In the demonstrative inflection, the demonstratives have lost gender sensitivity and just male form of them used for both male and female nouns while the main noun of the demonsrative phrase lost the gender sensitivity in favor of female agreemnent, like "vî/wî lawik-ê" (this/that.Oblique.Male boy.Oblique.Female) "vî/wî keçik-ê"(this/that.Oblique. Male girl.Oblique.Female). Furthermore, in the Northern variety of Northern Kurdish, the oblique inflection of definitive-nonspecific nouns has been lost due to Turkish influence. Last but not least, in all of the selected varieties, the young interviewees are less sensetive to gender agreement then olders.

\section{Kurte}

Kurdîya kurmancî zimanekî xwedî zayenda rêzimanî ye. Zayenda navdêran di rewşa rasterast de an jî wextê navdêr bi serê xwe têne bikrananîn nayê fêmkirin. Ji bo zayenda navdêran bê zanîn, navdêr divê di rewşa tewandî de an jî di rewşa bangkirinê de bê bikaranîn. Dîsa di nav avanîya îzafeyê de partîkela îzafeyê zayenda navdêran nîşan dide. Kurdîya kurmancî xwedî gelek devokan e û bikaranîna zayendê li gor devokan hin caran form diguherîne û di hin devokan de jî hessasîyeta zayendê ji holê rabûye. Di vê xebatê de sê devokên kurmancî ji hêla zayenda rewşan ve hatine analîzkirin. Ev devok devokên başûrê rojhilat, bakur û başûrê rojavayê ne. Senfinadina van devokan li gor xebatên herî dawî ne yên ku li ser devokên kurdî hatine kirin. Li jêr wê bi hurgilî behsa wê sinifandinê bê kirin. Ji bo devoka başûrê rojhilat gundekî Beytuşşebaba Şirnexê; ji bo devoka başûrê rojava Bajarê Semsûrê û ji bo devoka bakur jî gundekî bajarê Muşê hate hilbijartin. Ji bo analîza van devokan, ji hêla nivîskarê vê gotarê ve amûreke pîvandinê hatîye pêşxitin. Ev amûr ji pêncî û pênc pirsan pêk tê. Ev pirs bi tirkî ji axêveran hatine pirsin û bersivên wan bi kurdî hatine standin. Lewra kurmancî di nav guherîneke (an jî asîmîlasyoneke) gelek bi lez de ye, axêverên heremekê li gor emr û zayenda xwe, dibe ku ji bo heman formên rêzimanî formên cuda bikar bînin. Loma jî, axêver ji hêla temen; kal, navsere, ciwan û ji hêla zayendê; weku jin û mêr hatine dabeşkirin. Di encama vê xebatê de tiştên ku hatine bidestxistin, di devokên başûrê rojhilat û başûrê rojava de her çiqas zayenda rewşan hema hema wek kurmancîya standart be jî di devoka bakur de, navdêrên nedîyar û rengdêr û cînavdên nîşanê ji hêla zayendê ve hessasîyeta xwe wenda kirine. Di navdêrên dîyar yên nespesîfîk de devoka bakur, ji ber bandora tirkî paşgirên tewangê bikar neanîne. Dîsa di hemû devokan de axêverên ciwan li gor axêverên temendirêj kêmtir hessasîyet nişanê bikaranîna zayendê dane.

Bêjeyên Anaxtar: Kurdîya Kurmancî, Zayend, Devok, Tewang, , Rewşa Bangkirinê, Dîyar, Nedîyar. 


\section{Destpêk}

Peyva “zayend”ê (gender) ji "gennus" a (cure, beş) latînî tê. Li gor Hockett, zayenda zimanan di encama senifandina meneyî (wateyî?), morfolojik an jî fonolojik ya navdêran de derdikeve meydanê. Zimanekî dikare xwedîyê du an jî zêdetir zayendan be. Hin navdêrên di nav grubeke zayendê de cih girtî dibin ku ji hêla bîyolojîk ve jî xwedî heman zayendê bin. Hin caran jî zayenda bîyolojîk li ser senifandina navdêran bibandor nîne (Corbett, 1991: 1). Loma jî di hin zimanên dunyayê de senifandina navdêran wek "zayend"a wan tê te'rîfkirin, lê di hinekan de ji bo vê senifandinê "beșên navdêran" tê bikaranîn. Hin zimanên dunyayê tenê xwedî zayenda leksîkî ne û hinên din jî hem xwedî zayenda leksîkî hem jî ya rêzimanî ne. Mesela, tirkî xwedî zayenda leksîkî ye. Lewra navdêr ji hêla rêzimanî ve tu carî nasinifin. Lê hin navdêr hene ku di tirkî de ji wateya leksîkî ya wan navdêran zayenda wan ya bîyolojîk tê fêmkirin; wek, "tavuk" (mirîşk), "horoz" (dîk) (Aksan, 2015: 87).

Wextê wek kategorîyeke navdêrî behsa zayendê tê kirin, tişta tê qestkirin ne zayenda leksîkî lê zayenda rêzimanî ye. Di zayenda rêzimanî de, zayenda (senifa) navdêran ne tenê ji meneya wan navdêran lê ji forma wan ya rêzimanî jî tê fêmkirin. Mesela, di Almanî de wextê navdêrekê di nav kategorîya navdêrên nêr de be partîkela "der", wextê di nav kategorîya navdêrên mê de be partîkela "die" û wextê di nav kategorîya navdêrên notr de be partîkela "das" digire. Dîsa, li gor Corbett û gelek nivîskarên din wek (Ortmann, 1988: 62) tişta ku zimanên xwedî zayenda rêzimanî dîyar dikin rêkkeftina (agrement) navdêran ya bi hêmanên din yên hevok an frazan re ye (Haig, 2000: 2).

Hebûna zayendê di zimanekî de ji bo axêverên wî zimanî hêsanîyan çê dike. Mesela, zayend wê îmakanê dide ziman ku navdêrên wek hev tên nivîsîn lê mena wan cuda ne, ji hev cuda bibin (Akin, 2005: 2). Mesela di kurmancî de peyva "mal”ê eger di mena "cihê ku lê tê jîyîn" bê bikaranîn wek mê tê nîşankirin (mala min), lê eger di mena "xwedîbûna tiştekî" de bê bikaranîn wê demê jî nêr tê îşaretkirin (malê dunyayê).

Di kurdî de zayenda rêzimanî heye. Xebatên li ser zayenda di kurmancî de hatî kirin heta Jardîn diçe. Di wê xebata xwe de Jardîn dibêje, navdêr û regdêr bi $\{-a\}$ û $\{$-ê\}yê diqedin û yên bi \{-a\}yê diqedin mê yên bi \{-ê\}yê diqedin jî nêr in (MacKenzie, 1954: 529). Xebateke din ya bingehîn ya li ser zayenda di kurmancî de hatî kirin xebata Bedir Han û Lescot (2005) e. Pey van xebatan di pirtûkên rêzimana kurmancî de tenê ji hêla rêkkeftinê ve li ser zayenda kurmancî hatîye sekinîn. Di ferhengên kurmancî de jî gelek girîngî ji bo mijara zayendê nehatiye dayîn û di gelek ferhengên kurmancî de zayenda navdêran li ber wan nehatiye nivîsîn; wek Ferhenga Îzolî (1991) û ya Torî (1999) (Akın, 2005: 3). Heta destpêka sedsala bîstan xebatên rêk û pêk, qasî em dizanin, li ser zayenda kurmancî nehatine kirin. Di destpêka sedsala bîst û yekan de Haig û Opengîn li ser vê mijarê bi awayekî zanistî kûr bûne. 
Di kurmancî de navdêr di bin du zayendan de tên senifandin; yên nêr û yên mê. Eger navdêr di rewşa tewandî yan jî rewşa bangkirinê de; yan jî di nav îzafeyê de wek yekjimar neyêne bikaranîn, di derbarê zayenda navdêrên kurmancî de tu agahî dest nakeve (Haig, 2000: 4). Yanê, navdêr bi serê xwe û di rewşa rasterast de tu agahî di derbarê zayenda xwe de nadin. Eger em bikaranîna paşgirên zayendê yên kurmancî di nav tabloyekê de bidin wê wiha be (Tan, 2015; Bedîr Han û Lescot, 2004; Taş, 2013; Ekîncî, 2007; Adak, Aydin û yên din, 2016; Samûr, 2012; Komxebata kurmancîyê, 2016);

Tablo 1: Di Kurmancî de Paşgirên Zayendê

\begin{tabular}{|c|c|c|c|c|c|c|c|}
\hline & Rewş & a Tewand & & & $\begin{array}{l}\text { Rewşa } \\
\text { Bangkirinê }\end{array}$ & $\begin{array}{l}\text { Avan } \\
\text { Îzafe }\end{array}$ & \\
\hline & $\begin{array}{l}\text { Dîya } \\
\text { r }\end{array}$ & Nedîyar & $\begin{array}{l}\text { Rengdêrên } \\
\text { Nîşanê }\end{array}$ & $\begin{array}{l}\text { Cînavkê } \\
\text { n } \\
\text { Nîşanê }\end{array}$ & & $\begin{array}{l}\text { Dîya } \\
\text { r }\end{array}$ & $\begin{array}{l}\text { Nedîya } \\
\text { r }\end{array}$ \\
\hline Nêr & $-\hat{\imath}$ & -ekî & wî/vî... -̂̂ & wî & -0 & -ê & -ekî \\
\hline Mê & -ê & -ekê & wîlvê... -ê & wê & -ê & $-a$ & $\begin{array}{l}\text {-eke/- } \\
\text { eka }\end{array}$ \\
\hline Pirjimar & -an & -inan & $\begin{array}{l}\text { wan/van...- } \\
\text { an }\end{array}$ & wan & -(i)no & -ên & -ine \\
\hline
\end{tabular}

Di vê xebatê de wê li ser zayendê bê rawestan. Her wekî di tabloya jorîn de jî hatiye dîyarkirin zayend di rewşa tewandî, rewşa bangkirinê û di îzafeyê de heye. Di vê xebatê de em ê li ser zayenda di rewşa tewandî û di rewşa bangkirinê de bisekinin. Di pirtûkên rêzimanan de jixwe ev bikararanîna zayendê bi hurgilî hatiye te'rîfkirin. Lê belê her wekî tê zanîn kurmancî xwedî gelek devokan e û bikaranîna zayendan li gor devokan diguherin. Loma jî di vê xebatê de wê li ser zayenda rewşan di devokên bakur, başûrê rojhilat û başûrê rojava de bê sekinîn. Ev devokên hatî hilbijartin di nav xwe de jî xwedîyê bikaranîneke homojen nînin. Eger her devok bi hemû varyasyonên xwe ve di nav vê xebatê de cih bigirtana wê xebatê gelek berfireh bûya. Loma jî hem hemû devok nehatine hilbijartin hem jîjji devokên hilbijartî tenê cihek û hun kes hatine neqandin. Di vê çarçoveyê de, divê di serî de li ser senifandina devokên kurmancî bê sekinîn, paşê jî behsa girseya axêverên ji bo vê analîzê hatî hilbijaritin bê kirin. Wek dawî jî divê di derbarê amûra pîvandinê ya zayenda di rewşa tewandî de agahî bê dayîn ku ev amûr ji hêla nivîskarê vê gotarê ve hatîye pêşxistin. 
Devokên kurmancî heta niha ji hêla kêm nivîskaran ve bi awayekî zanistî hatine senifandin. Mesela, Zinar (2009) senifandineke devokên kurmancî kirîye lê ev senifandina xwe bi delîlên zanistî nîşan nedaye. Wî devokên kurmancî di bin deh devokan de senifandine; Devoka Afrînî, Devoka Cizîrî, Devoka Sincarî, Devoka Behdînî, Devoka Hekarî, Devoka Şikakî, Devoka Bazîdî, Devoka Botanî, Devoka Şemdînanî, Devoka Rojavayî (Zinar, 2009; 16). Lewra ev senifandin ji delîlên zanistî mehrûm in em ê vê wek bingeh negirin. Ji delîlên zanistî qesta me ew e; wextê devok têne senifandin divê ne tenê cudahîyên leksîkî yên devokan bên danberhevkirin lê bi awayekî sîstematîk cudahîyên fonolojîk, morfolojîk, sentaksî û yên leksîkî bi hemu aiyên xwe ve bên nîşandan.

Xebata Haig û Öpengin (2014) ya bi nave "Regional Variation in Kurmanji: A Preliminary Classification of Dialects" (Di kurmancî de Varyasyona Heremî: Senifandineke Destpêkî ya Devokan) di warê senifandina devokan de xebateke baş e. Di vê xebatê de devokên kurmancî di bin pênc beşan de hatine senifandin; Devoka başûrê rojhilat, devoka başûr, devoka bakur, devoka başûrê rojava, devoka bakurê rojava.

Devoka başûrê rojhilat: Wek devoka behdînî jî tê zanîn ku li heremên Hakkarî û Duhokê tê axaftin. axaftin.

Devoka başûr: Li Mêrdîn, Êlih, Dîyarbekir, Şirnex, Riha û Hesekeyê tê

Devoka bakur: Wek devoka Serhedê jî tê zanîn. Mûş, Erzirum, Agirî, Bedlîs, Çewlig, Dîyarbekir û hin deverên Wanê tê axaftin.

Devoka başûrê rojava: Li Semsûr, Entep, qismeke Rihayê û Helebê tê axaftin. 2014)

Devoka bakurê rojava: Mereş, Meletî, Sîwasê tê axaftin (Haig û Öpengin,

Di vê xebatê de wê ev senifandin wek bingeh bê girtin. Her çiqas di vê senifandinê de Şirnex di nav devoka başûr de cih bigire jî, mintiqa ku xebata qadê ya vê xebatê lê hatî kirin di nav sînorên devoka başûrê rojhilat de ye.

Ev xebat wextê tetbîqê qadê bû, hin pirsgirêk hatin meydanê. Lewra kurmancî di nav gurehîneke gelek lez de (asîmîlasyon) ye û hemû nifşên axêverên vî zimanî wek hev naxivin. Di vê guherînê de duzimanîtî jî xwedî bandoreke gelek mezin e. Her wekî Öpengin gotî "mirov dikare dîyar bike ku cimaeta zimanî ya kurdîyê xwedanê qerekterê duzimanîya civakî ye, bi kurdî û bi tirkî" (Öpengin, 2011: 37). Bi taybetî wextê mijar mijareke hessas wek zayendê be, wê demê gelek bikaranînên cuda di navbera cenerasyonan de derdikevin holê. Loma jî, wextê ev pirsên amûra pîvandinê li axêveran hate pirsîn ji sê cenerasyonan pirs hatin pirsîn; yên ciwan, yên navsere û yên kal. Dîsa lewra mijara zayendê li hember zayenda biyolojik ya axêveran hessas e û di kurmancî de jî kesê ku refere lê tê kirin ji bo mijara zayendê girîng e, axêver ne tenê ji hêla 
emr ve lê ji hêla zayenda bîyolojîk ve jî wek jin û mêr hatin senifandin. Di encamê de li her heremê ji şeş kesan ev pirs hatin pirsin; ciwan-mêr, ciwan-jin, navseremêr, navsere-jin, kal-mêr û kal-jin.

Di vê xebatê de di serî de li ser paşgirên zayendê di rewşa tewandî û rewşa rasterast de hatîye sekinîn. Paşê li ser bikaranîna paşgirên zayendê di devokên hilbijartî de hatîye sekinîn. Di encamê de jî bi gelenperî behsa destketîyan hatîye kirin.

\section{Di Kurmancî de Bikaranîna Zayenda Rewşan}

Her wekî tê zanîn di kurmancî de ji hêla morfolojîk ve sê rewş hene rewşa rasterast, rewşa tewandî û rewşa bangkirinê. Di rewşa rasterast de tu paşgirên zayend an jî hejmarê nayên bikaranîn. Loma jî di vê xebatê de wê behsa vê rewşê neyê kirin. Paşgirên zayendê tenê di rewşa tewandî û di rewşa bangkirinê de têne bikaranîn. Loma jî wê ewil behsa zayenda di rewşa tewandî de û paşê jî wê behsa zayenda di rewşa bangkirinê de bê kirin.

\subsection{Di Rewşa Tewandî de Zayend}

Di rewşa tewandî de tewanga navdêran bi sê awayên kişandinê dertên pêşberî me; dîyar, nedîyar, rengdêr û cinavkên nîşanê).

Di rewşa tewandî de navdêrên yekjimar wextê dîyar bin, ji hêla zayenda xwe ve allomorfên paşgira zayendê digirin. Navdêrên mê paşgira \{-ê\}yê û yên nêr jî paşgira \{-î\}yê distînin. Navdêr wextê pirjimar û dîyar bin paşgir dibe \{-an\} (Tan, 2015; Bedîr Han û Lescot, 2004; Taş, 2013; Ekîncî, 2007; Adak, Aydin û yên din, 2016; Samûr, 2012). Mesela,

$(1)^{2}$

\begin{tabular}{|l|l|l|l|l|l|}
\hline Ez & Kenan- & $-\hat{\imath}$ & di- & -bîn- & -im \\
\hline 1YJ.RST. & Ndr.- & -TEW.Nêr. & Pêș.r.r.- & -dîtin:k.d.n.- & -1YJ. \\
\hline
\end{tabular}

\begin{tabular}{|l|l|l|l|l|l|}
\hline Ez & Şukran- & -ê & di- & -bîn- & -im \\
\hline 1YJ.RST. & Ndr.- & -TEW.Mê. & Pêș.r.r. & -dîtin:k.d.n.- & -1YJ. \\
\hline
\end{tabular}

2 Kurtkirinên di vê gotarê de hatî bikaranîn di serê gotarê de di nav tabloyekê de hatine dayîn. 
(3)

\begin{tabular}{|l|l|l|l|l|l|}
\hline Ez & heval- & -an & di- & -bîn- & -im \\
\hline 1YJ.RST. & Ndr.- & -TEW.PJ. & Pêş.r.r.- & -dîtin:k.d.n.- & -1YJ. \\
\hline
\end{tabular}

Di mînaka (1)î de navdêra "Kenan" çima navdêreke nêr e bi $\{-1\}$ yê; di ya (2)yan de navdêra "Şukran" çima navdêreke mê ye bi \{-ê\}yê û di mînaka (3)yan de jî çima navdêra "heval” bi awayekî pirjimar hatiye bikaranîn bê hessesîyeta zayenda navdêrê bi \{-an\}ê tewîyaye.

Navdêrên nêr di gelek devokên kurmancî de yan nayên tewandin yan jî bi awayekî din tên tewandin. Awayekî din ya tewandina navdêrên nêr wiha ye; eger di nav navdêra nêr ya tewandî de dengê /e/ an jî /a/ hebe ew navdêr dibe /ê/ (Tan, 2015; Bedîr Han û Lescot, 2004; Adak, Aydin û yên din, 2016). Ji vê re di zimanzanîyê de "umlaut" yan jî kişandin (rising) tê gotin (Yonat, Notên Dersa Morofolojîya Kurdî). Eger em mînaka jorê bi vî awayî bikêşin wê wiha be;

\begin{tabular}{|l|l|l|l|l|}
\hline Ez & Kenên & di- & -bîn- & -im \\
\hline 1YJ.RST. & $\begin{array}{l}\text { Kenan.TEW.N } \\
\text { êr. }\end{array}$ & Pêş.r.r.- & -dîtin:k.d.n.- & -1YJ. \\
\hline
\end{tabular}

Her wekî ji mînakê jî tê fêmkirin dengê /a/yê ya di nav navdêra nêr ya “Kenan” de kişiyaye û bûye /ê/.

Ji bilî vê îstîsnayê, di kurdî de wextê navdêr dîyar in û di rewşa tewandî de tên bikaranîn, bikaranîneke din ya ku di bin bandora zimanê tirkî de pêş ketîye, dertê pêşberî me. Ev jî cudahîya rewşa spesîfîk û nespesîfîk e. Di tirkî de navdêr wextê spesîfîk bin paşgira rewşê digirên lê wextê nespesîfîk bin paşgirê nagirin. Mesela,

(a) Yalın mektubu yazıyor. (Yalin nameyê dinivîse)

(b) Yalın mektub yazar. (Yalin nameyan/nameyê dinivîse)

Di vir de di (a)yê de "mektub" (name) "name”yeke spesîfîk e. Yanê derbarê wê de agahîyên pêş (old information) hene. Loma jî paşgira rewşê \{-u\}yê standiye. Lê di (b)yê de lewra "mektub" (name) ne nameyeke spesifik e, loma jî tu paşgirê nestandiye (İşsever, 2006; 44). Di kurdî de, her wekî ji wergerên wan hevokan jî tê fêmkirin, navdêra "name" di rewşa spesîfîk de paşgira yekjimariyê distîne û di rewşa nespesîfîk de yan paşgira pirjimarîyê yan jî ya yekjimariyê distîne. Yanê di her halî de, navdêr mecbûr e bitewe. Lê di hin devokên kurmancî de, ji ber bandora tirkî, navdêrên di halê nespesîfîk de hatî bikaranîn, wek tirkî bê nîşan dimînin, yanê natewin. 
Wextê navdêr di rewşa tewandî de lê nedîyar tên kişandin, navdêrên yekjimar ewil paşgira nedîyarîyê \{-ek\}ê distînin û paşê navdêrên nêr paşgira \{-î\}yê û yên mê jî paşgira \{-ê\}yê distînin. Eger navdêr pirjimar bê kişandin du form dertên pêşberî me. Forma ewil navdêr pêșî paşgira nedîyarîyê ya pirjimar \{-in\}ê û paşê jî paşgira pirjimarîyê ya tewangê \{-an\}ê distîne. Di forma duyem de navdêr wek navdêra dîyar tê tewandin lê beriya navdêrê bêjeya "hin/hinek/hindik/hinde" tê bikaranîn (Tan, 2015; Bedîr Han û Lescot, 2004; Taş, 2013; Ekîncî, 2007; Adak, Aydin û yên din, 2016; Samûr, 2012). Mesela,

(1)

\begin{tabular}{|l|l|l|l|l|l|l|}
\hline Ez & mêr- & -ek- & -i & di- & -bîn- & -im \\
\hline 1YJ.RST. & Ndr.- & -paş.NeDyr.YJ.- & -TEW.Nêr. & Pêş.r.r.- & -dîtin:k.d.n.- & -1YJ. \\
\hline
\end{tabular}

(2)

\begin{tabular}{|l|l|l|l|l|l|l|}
\hline Ez & jin- & -ek- & -ê & di- & -bîn- & -im \\
\hline 1YJ.RST. & Ndr.- & -Paş.NeDyr.YJ- & -TEW.Mê. & Pêş.r.r.- & -dîtin:k.d.n.- & -1YJ. \\
\hline
\end{tabular}

(3)

\begin{tabular}{|l|l|l|l|l|l|l|}
\hline Ez & mêr- & -in- & -an & di- & -bîn- & -im \\
\hline 1YJ.RST. & Ndr- & -Paş.NeDyr.PJ.- & -TEW.PJ & Pêș.r.r.- & -ditin:k.d.n.- & -1YJ. \\
\hline
\end{tabular}

(1) ji bo kişandina navdêrên nêr bi awayekî nedîyar, (2) ji bo kişandina navdêrên mê bi awayekî nedîyar û (3) jî ji bo kişandina navdêran bi awayekî nedîyar û pirjimar mînak in.

Di kurmancî de wextê rengdêrên nîşanê di rewşa tewandî de tên bikaranîn ev rengdêr jî wek navdêran ditewin. Rengdêrên nîşanê ji hêla nêzîkbûn û dûrbûn, rewşa rasterast û rewşa tewandî, zayend û hejmarê ve diguherin (Tan, 2015; Bedîr Han û Lescot, 2004; Taş, 2013; Ekîncî, 2007; Adak, Aydin û yên din, 2016). Eger em bi tabloyekê bidin wê wiha be; 
Tablo 2: Di Rewşa Tewandî de Cînavk û Rengdêrên Nișanê

\begin{tabular}{|l|l|l|l|}
\hline Zayend û Hejmar & Nêzîk û Dûr & $\begin{array}{l}\text { Rengdêrên } \\
\text { Nîşanê Rewşa } \\
\text { Tewandî }\end{array}$ & $\begin{array}{l}\text { Cînavkên Nîşanê } \\
\text { Rewşa Tewandî }\end{array}$ \\
\hline \multirow{2}{*}{ Nêr } & Nêzîk & Vî ....... î & wî \\
\cline { 2 - 3 } & Dûr & Wî .......î & \\
\hline Mê & Nêzîk & Vê .......ề & \multirow{2}{*}{ wê } \\
\cline { 2 - 3 } & Dûr & Wê .......ê & \multirow{2}{*}{ Wan } \\
\hline Pirjimar & Nêzîk & Van ........an & \multirow{2}{*}{} \\
\cline { 2 - 3 } & Dûr & Wan .....an & \\
\hline
\end{tabular}

Her wekî ji tabloyê jî tê dîtin navdêr wextê bi rengdêreke nîşanê ve di rewşa tewandî de tên bikaranîn ji hêla zayend, hejmar, nêzîkî û dûrî ve diguherîn. Di kurmancî de rengdêrên nîşanê yên dûr û cînavkên kesî yên şexsê sêyem (Wî, wê, wan) heman bêje ne. Eger em mînakan bidin;

(1)

\begin{tabular}{|l|l|l|l|l|l|l|l|}
\hline Ez & vî/wî & lawik- & $-\hat{\imath}$ & hez & di- & -k- & -im \\
\hline 1YJ.RST. & $\begin{array}{l}\text { Rgd.Nîş.TEW. } \\
\text { Nêr.Nêz/dûr }\end{array}$ & Ndr.- & -TEW.Nêr & Ndr. & Pêş.r.r.- & -kirin:k.d.n- & -1YJ. \\
\hline
\end{tabular}

(2)

\begin{tabular}{|l|l|l|l|l|l|l|l|}
\hline Ez & vê/wê & keçik- & -ê & hez & di- & $-k-$ & -im \\
\hline 1YJ.RST. & $\begin{array}{l}\text { Rgd.Nîş.TEW. } \\
\text { Mê.Nêz/Dûr }\end{array}$ & Ndr.- & -TEW.Mê & Ndr. & $\begin{array}{l}\text { Pêş.r. } \\
\text { r.- }\end{array}$ & $\begin{array}{l}- \\
\text { kirin:k.d.n } \\
--\end{array}$ & -1YJ. \\
\hline
\end{tabular}


Di Devokên Kurdîya Kurmancî de Zayenda Rewşên Morfolojîk (Mînakên Devokên Bakur, Başûrê Rojhilat û Başûrê Rojavayê)

(3)

\begin{tabular}{|c|c|c|c|c|c|c|c|}
\hline $\mathrm{Ez}$ & van & lawik & -an & hez & di- & $-k-$ & -im \\
\hline 1YJ.RST & $\begin{array}{l}\text { Rgd.Nîş.TEW.PJ.Nêz/ } \\
\text { Dûr }\end{array}$ & Ndr. & TEW.PJ & Ndr & $\begin{array}{l}\text { Pêş.r. } \\
\text { r.- }\end{array}$ & kirin:k.d.n & $-1 Y J$. \\
\hline
\end{tabular}

(1) ji bo navdêrên nêr, (2) ji bo navdêrên mê û (3) jî ji bo navdêrên pirjimar mînakên bikarananîna rengdêrên nîșanê yên di rewşa tewandî de ne. Ev bikaranîn di hemû devokên kurmancî de wek hev nînin. Bi taybetî di devoka Serhedê de û li mintiqa Dêrsimê kişandinna rengdêrên nîşanê ji hêla zayendê ve notralîze bûye ((Haig, 2000: 6-7).

\subsection{Rewșa Bangkirinê}

Di rewşa bangkirinê de navdêr wek rewşa tewandî di kişandina yekjimar de li hember zayendê hessas e lê di kişandina pirjimaran de ne hessas e. Di rewşa bangkirinê de navdêrên nêr paşgira \{-o\}yê, yên mê paşgira \{-ê\}yê distînin. Wextê navdêr pirjimar bê kişandin paşgira $\{$-(i)no\} tê bikaranîn (Tan, 2015; Bedîr Han û Lescot, 2004; Taş, 2013; Ekîncî, 2007; Adak, Aydin û yên din, 2016). Mesela,

\begin{tabular}{|l|l|}
\hline Xort- & -0 \\
\hline Ndr.- & -Paş.Bng.Nêr \\
\hline
\end{tabular}

(2)

\begin{tabular}{|l|l|}
\hline Xwîşk- & -ê \\
\hline Ndr.- & - Paş.Bng.Mê \\
\hline
\end{tabular}

(3)

\begin{tabular}{|l|l}
\hline Gundî- & -no \\
\hline Ndr.- & -Paş.Bng.PJ.
\end{tabular}

(1) ji bo kişandina navdêrên nêr, (2) ji bo kişandina navdêrên mê û (3) jî ji bo kişandina pirjimar di rewşa bangkirinê de ne. Di devokan de dibe ku hin caran navdêrên mê paşgira navdêrên nêr bistînin wek "Dîlo" ji bo "Dîlanê" û dîsa hin caran jî navdêrên nêr paşgira navdêrên mê distînin wek "Ekê" ji bo "Ekremo". Lê lewra ew ne standard in di vê beșê de wê li ser van neyê sekinîn. 
(1) ji bo kişandina navdêrên nêr, (2) ji bo kişandina navdêrên mê û (3) jî ji bo kişandina pirjimar di rewşa bangkirinê de ne. Di devokan de dibe ku hin caran navdêrên mê paşgira navdêrên nêr bistînin wek "Dîlo" ji bo "Dîlanê" û dîsa hin caran jî navdêrên nêr paşgira navdêrên mê distînin wek "Ekê" ji bo "Ekremo". Lê lewra ew ne standard in di vê beşê de wê li ser van neyê sekinîn.

\subsection{Amûra Pîvandinê ya Zayenda Rewșên Morfolojîk yên Kurmancî}

Amûra pîvandinê ya zayenda rewşan ji hêla nivîskarê vê gotarê ve hatîye pêşxistin. Pêşî ev amûra pîvandinê di bin du beşan de hatîye dabeşkirin; kişandina rewşa tewandî û kişandina rewşa bangkirinê. Di kişandina rewşa tewandî de navdêr pêşiyê ji hêla fonksîyonên xwe yên rêzimanî ve hatine dabeşkirin. Ev kişandin di bin çar beşan de ne; dîyar, dîyar-nespesîfîk, nedîyar û rengdêr û cînavkên nîşanê. Li jorê behsa van hate kirin. Paşê navdêr li gor zayend û hejmara xwe di bin sê beşan de hatine dabeşkirin; nêr, mê û pirjimar. Pey vê dabeşkirinê navdêrên nêr û mê ji hêla meneya xwe ve jî hatine dabeşkirin; yên însan, yên neînsan, yên mervantiyê, yên necandar, yên qerzkirî (ev du beş in; yên ku peyveke kurmancî ji bo wê heyî (wek "yağ"a (rûn) tirkî) û yên ku peyveke kurmancî ji bo wê tuneyî (wek, "hemşire”ya Farisî). Pey vê, navdêrên pirjimar wek yên tên hejmartin û yên nayên hejmartin hatine dabeșkirin. Di dawîyê de navdêrên cot-zayend hatin bikaranîn. Eger ev sinifandin di nav tabloyekê de bê dayîn wê wiha be;

Tablo 3: Amûra Pîvandinê ya Zayenda Rewşa Tewandî

\begin{tabular}{|c|c|c|c|c|}
\hline \multicolumn{5}{|c|}{ Rewşa Tewandî } \\
\hline Hejmar & Dîyar & $\begin{array}{l}\text { Dîyar- } \\
\text { Nespesîfîk }\end{array}$ & Nedîyar & $\begin{array}{l}\text { Rengdêr û Cînavkên } \\
\text { Nîşanê }\end{array}$ \\
\hline Yekjimar & \multicolumn{4}{|c|}{$\begin{array}{l}\text { yên însan, yên neînsan, yên mervantiyê, yên necandar, yên qerzkirî } \\
\text { (ev du beş in; yên ku peyveke kurmancî ji bo wê heyî (wek "yağ"a } \\
\text { (rûn) tirkî) û yên ku peyveke kurmancî ji bo wê tuneyî (wek, } \\
\text { "hemşire"ya erebî), Yên cot-zayend. }\end{array}$} \\
\hline Pirjimar & \multicolumn{4}{|c|}{ Navdêrên tên hejmartin û yên nayên hejmartin. } \\
\hline
\end{tabular}

Di encama vê senifandinê de amûreke pîvanê ya ji pêncî û pênc pirsan pêkhatî derket meydanê. Ev pirs bi tirkî li axêveran hatiye pirsîn û bi kurdî cewabên wan hatine hildan. Ev amûra pîvandinê ya zayenda rewşa tewandî di pêvekê de ye. 
Amûra pîvandinê ya ji bo zayenda rewşa bangkirinê ji şeş pirsan pêk tê. Pêşî navdêr li gor zayend û hejmara xwe di bin sê binbeşan de hatine dabeşkirin; yên nêr, yên mê û yên pirjimar. Paşê ev beş di bin du beşan de dîsa hatine dabeşkirin; navdêrên taybet û navdêrên cînsî. Di encamê de jî şeş pirs derketine meydanê. Ev amûra pîvanê jî di pêvekê de ye.

\section{Di Devokên Kurmancî de Zayenda Rewşan}

Di vê xebatê de sê devokên kurmancî ji hêla zayenda rewşan ve hatine nirxandin; Devoka başûrê rojhilat, devoka bakur û devoka başûrê rojava. Niha ev devok wê ji hêla zayenda rewşan ve bên nirxandin.

\subsection{Devoka Başûrê Rojhilat}

Ji bo vê devokê gundê Çeman (Ayvalik) ya bajaroka Beytuşşebabê ya li ser Şirnexê hatiye hilbijartin.

\subsubsection{Kişandina Navdêrên Dîyar}

Di vê devokê de wextê navdêr rewşa tewandî de û bi awayekî dîyar bê kişandin, navdêrên nêr bi $\{-1\}$ \}yê ve na, lê di vê devokê de ev navdêrên nêr bi paşgir $\{-i\} y e ̂$ ve ditewin. Mesela,

Mînak: (Ş3.N.Mr.), (Ş.K.J), (Ş.C.J).

\begin{tabular}{|l|l|l|}
\hline Ew & zava-yi & di-bîn-itin \\
3YJ.RST. & Ndr-TEW.Nêr & $\begin{array}{l}\text { Pêş.r.r.-dîtin:k.d.n.- } \\
\text { 3YJ.patîkel }\end{array}$ \\
\hline
\end{tabular}

Di vê derê de cihê ku paşgira tewangê ya ji bo navdêrên nêr $\{-y \hat{i}\}$ bê bikaranîn, paşgira \{-yi\}yê hatiye bikaranîn. Ji bilî vê, ji hemû aliyên xwe ve, di vê devokê de navdêrên diyar wek navdêrên Kurmanciya standart têne kişandin.

Divê bê behskirin ku navdêrên refereyê herdu zayendan dikin di vê devokê de wek kurmancîya standart nêr hatine kişandin. Mesela,

Mînak: (Ş.C.J.), (Ş.K.J.)

\begin{tabular}{|l|l|l|}
\hline Ez & heval-i & di-bîn-im \\
1YJ.RST. & $\begin{array}{l}\text { Nvd.(cotzayend)- } \\
\text { TEW.Nêr. }\end{array}$ & Pêş.r.r.-dîtin:k.d.n.-1YJ. \\
\hline
\end{tabular}

Di vê mînakê de navdêra cotzayend ya "heval" wextê kesê ku refere lê tê kirin neyê zanîn, di vê devokê de wek nêr tê bikaranîn. 


\subsubsection{Kişandina Navdêrên Dîyar yên Nespesîfîk}

Kişandina navêdêrên dîyar yên nespesîfîk, her wekî li jorê jî behsa wê hatîye kirin, dibe ku ji ber bandora tirkî bê paşgir bê bikaranîn. Di vê devokê de tenê axêvera jin ya navsere paşgir ji bo vê rewşê bikar neanîye. Ji bilî wê, axêver yan navdêrê wek pirjimar yan jî wek nedîyar kişandine.

(1) (Ş.N.Mr)

\begin{tabular}{|l|l|l|l|l|l|l|}
\hline Em & her & eyd-a & beran-a & ser & jê & di-k-en \\
\hline 1PJ.RST. & her & $\begin{array}{l}\text { Ndr.- } \\
\text { TEW.PJ }\end{array}$ & $\begin{array}{l}\text { Ndr.- } \\
\text { TEW.PJ }\end{array}$ & Ndr. & Daçek. & $\begin{array}{l}\text { Pêş.r.r.- } \\
\text { kirin.k.d.n.- } \\
\text { 3PJ. }\end{array}$ \\
\hline
\end{tabular}

(2) (\$̧.K.J)

\begin{tabular}{|l|l|l|l|l|l|}
\hline Her & eydî-k-î & beran-ek-î & ser & jê & di-k-in \\
\hline Her & $\begin{array}{l}\text { Ndr.- } \\
\text { Paş.NeDyr.- } \\
\text { TEW.Nêr }\end{array}$ & $\begin{array}{l}\text { Ndr.- } \\
\text { Paş.NeDyr.- } \\
\text { Nêr }\end{array}$ & Ndr. & Daçek & $\begin{array}{l}\text { Pêş.r.r.- } \\
\text { kirin:k.d.n.-3PJ. }\end{array}$ \\
\hline
\end{tabular}

(3) (S..N.J)

\begin{tabular}{|l|l|l|l|l|l|l|}
\hline Em & hemi & eyd-yan & beran & ser & jê & di-k-en \\
$\begin{array}{l}\text { 1PJ.RS } \\
\text { T. }\end{array}$ & hemî & $\begin{array}{l}\text { Ndr.- } \\
\text { TEW.PJ. }\end{array}$ & $\begin{array}{l}\text { Ndr.RS } \\
\text { T. }\end{array}$ & $\begin{array}{l}\text { Ndr } \\
\text {. }\end{array}$ & Daçek. & Pêş.r.r.-kirin:k.d.n.-3PJ. \\
\hline
\end{tabular}

Di van mînakan de navdêra nespesîfîk ya dîyar "beran" e. Loma wergera vê hevokê bo tirkî ev e; “Biz her bayramda koç keseriz.”. Her wekî tê dîtin lewra "koç" (beran) nespesîfîk e, loma jî nehatîye tewandin. Di mînaka (1)î de navdêr wek pirjimar hatîye kişandin; (2)yan de navdêr wek nedîyar û nêr hatîye kişandin. Ev bikaranîn wek bikaranîna (3)yan derasayî ye. Lê ji hêla gramatîk ve pirsgirêk tune ye. Lewra hatîye tewandin. Lê di mînaka (3)yan de navdêr nehatiye tewandin. Dikare bê gotin ku di vê derê de bandora tirkî heye.

\subsubsection{Kişandina Navdêrên Nedîyar}

Di halê nedîyar ya tewangê de di vê devokê de tu bikaranînên cuda tunene. Yanê, navdêrên nêr bi \{-ekî\}, navdêrên mê bi \{-ekê\} û yên pirjimar jî beriya navdêra tewîyayî bêjeya "hinde" hatîye bikaranîn û navdêr bi $\{-a(n)\} e ̂$ hatine tewandin. Di pirjimaran de pirî caran dengê /n/yê ya di dawîya $\{$-an\}ê de ketîye. 
Di vê derê de tişta balkêş ew bû ku axêvera jin ya ciwan û ya navsere di navdêrên cotzayend de rêkkeftina mê bi kar anîne. Mesela,

\begin{tabular}{|l|l|l|}
\hline Ez & heval-ek-ê & di-bîn-im \\
\hline 1YJ.RST. & $\begin{array}{l}\text { Ndr.-Paş.NeDyr.- } \\
\text { TEW.Mê }\end{array}$ & Pêş.r.r.-dîtin:k.d.n.-1YJ. \\
\hline
\end{tabular}

Heval her çiqas navdêreke cotzayend be û li gor standarda kurmancî di çarçoveya erênîya gelenper de divê nêr bê bikaranîn jî, ji hêla axêverên jin ve wek mê hatîye bikaranîn. Lewra jî, dikare bê gotin ku hin caran zayenda bîyolojîk ya axêver li ser rêkkeftinê bandor çêdike.

\subsubsection{Kişenadina Cînavk û Rengdêrên Nîşanê}

Bikaranîna cînavk û rengêdêrên nîşanê di vê devokê de dîsa wek kurmancîya standard e. Lê wekî di kişadina dîyar di vê derê de jî di şûna $\{-\hat{i}\}$ de $\{-i\}$ hatiye bikaranîn. Navdêrên cotzayend ${ }^{4}$ ji hêla axêverê mêr yê kal ve wek mê hatine kişandin. Sebebê vê bi me bi terciha axêver zêdetir xeletiyeke demdemî ve dikare bê ravekirin. Mesela,

\begin{tabular}{|l|l|l|l|l|}
\hline Ew & ê & wi & Zava-yi & di-bîn-îtin \\
\hline 3YJ.RST. & Îzf.Brf. & $\begin{array}{l}\text { Nîş.TEW.N } \\
\text { êr }\end{array}$ & $\begin{array}{l}\text { Nvd.- } \\
\text { TEW.Nêr }\end{array}$ & r.r.-dîtin:k.d.n.-3YJ. \\
\hline
\end{tabular}

Her wekî ji vê mînakê jî tê dîtin navdêra "Zava" bi cînavka nîșanê hatîye nîşandan û hem di şûna "wî" de "wi" hatiye bikaranîn û cihê ku navdêr bi "yî" ve were tewandin "yi" ve hatiye tewandin.

Eger em hemû bikaranînên kişandina navdêran di rewşa tewandî de bi tabloyekê bidin wê ev derê meydanê;

Tablo 4: Paşgirên Kișandinê yên Di Devoka Başûrê Rojhilat de

\begin{tabular}{|c|c|c|c|c|}
\hline & Dîyar & Dîyar-Nespesîfîk & Nedîyar & $\begin{array}{l}\text { Cînavk û rengdêrên } \\
\text { Nîşanê }\end{array}$ \\
\hline Nêr & $\{-i\}(\{-\hat{i}\}$ & \multirow{2}{*}{$\begin{array}{l}\text { Pirî caran paşgira } \\
\text { diyarê, hin canran } \\
\text { paşgira nedîyarîyê }\end{array}$} & $\begin{array}{l}(\text { ek)-\{-i\} / (ek) } \\
\{-\hat{i}\}\end{array}$ & vi .... $\{-i\} /$ vî...\{-î\} \\
\hline Mê & $\{-\hat{e}\}$ & & $(e k)-\{-e ̂\}$ & vê.... $\{-\hat{e}\}$ \\
\hline
\end{tabular}

4 Di hin çavkaniyan de di şûna "navdêrên cotzayend" terma "navdêrên notr” jî tê bikaranîn. 


\begin{tabular}{|l|l|l|l|l|l|}
\hline Pirjimar & $\{-a(n)\}$ & $\begin{array}{l}\text { û tenê carê jî bê } \\
\text { paşgir }\end{array}$ & $\begin{array}{l}\text { hinde } \ldots \\
a(n)\}\end{array}$ & va(n) ... & -a(n)\} \\
\hline
\end{tabular}

Her wekî ji tabloyê jî tê fêmkirin, tenê di navdêrên nêr de di şûna $\{-\hat{i}\}$ de $\{-i\}$ hatiye bikaranîn. Lê dîsa hin caran $\{-\hat{\imath}\}$ jî hatiye bikaranîn. Di pirjimaran de pirî caran dengê /n/yê ketîye. Wextê navdêr nedîyar û pirjimar hatine kişandin cihê ku \{-inan\} bê bikaranîn forma duyem ya nedîyarkirina pirjimaran hatiye bikaranîn ku di wê de bêjeya "hinde" tê beriya navdêrê.

\subsubsection{Rewşa Bangkirinê}

Rewşa bangkirinê di vê devokê de wek kurmancîya standard hatîye bikaranîn. Lê hin axêveran wextê navdêrên taybet di vê rewşê de bi kar anîne paşgirên pirjimariyê bi kar neanîne. Wek, cihê ku bibêjin "Kenano!” gotine "Kenan!"

\subsection{Devoka Bakur}

Ji bo vê devokê gundê Zîyaretê ya li ser navenda Mûşê hatîye hilbijartin. Pirsên amûra pîvandinê ji şeş axêveran hatine pirsîn.

\subsubsection{Kișandina Navdêrên Dîyar}

Di vê devokê de navdêrên mê wek kurdîya standart bi paşgira \{-ê\}yê ve ditewe. Navdêrên nêr paşgira tewangê $\{-1 \hat{\}}$ yê nastînin. Hin axêveran hin caran ji bo navdêrên nêr paşgira navdêrên mê bi kar anîne. Mesela,

Mînak: (M.C.J.)

\begin{tabular}{|l|l|l|}
\hline Ew & zava(y)-ê & di-bîn-e \\
\hline 3YJ.RST. & Ndr.(nêr)-TEW.Mê & Pêş.r.r.-dîtin:k.d.n.-3YJ. \\
\hline
\end{tabular}

Di vê mînakê de navdêra nêr "zava” her çiqas hem ji hêla bîyolojîk ve hem jî ji hêla rêzimanî ve nêr be jî, wek mê hatîye bikaranîn. Ev bikaranîn dikare bibe destpêka notralîzebûna paşgira tewanga dîyar. Lewra eger hem ji bo navdêrên nêr hem jî ji bo navdêrên mê paşgira \{-ê\} bê bikaranîn, tu nîşan namîne ji bo cudakirina zayenda gramatîk ya navdêran ya di halê dîyar de.

Ji bo navdêrên cotzayend jî pirî caran tu paşgir nehatine bikranîn. Lewra jî pirî caran navdêrên nêr di vê devokê de tu paşgir nagirin, dîsa di çarçoveya nêrtîya gelenperî de divê navdêrên cotzayend nêr bên kişandin, loma jî navdêrên cotzayend tu paşgirê nesitandine. 
Di Devokên Kurdîya Kurmancî de Zayenda Rewşên Morfolojîk (Mînakên Devokên Bakur, Başûrê Rojhilat û Başûrê Rojavayê)

Mînak: (M.N.Mr.), (M.K.J). (M.C.Mr.)

\begin{tabular}{|l|l|l|}
\hline Ez & heval & di-bîn-im \\
\hline 1YJ.RST. & Ndr. & Pêş.r.r.-dîtin:k.d.n.-1YJ. \\
\hline
\end{tabular}

Her wekî ji mînakê jî tê xwîyanê navdêra cotzayend "heval” tu paşgirê negirtîye di rewşa tewandî de.

\subsubsection{Kişandina Navdêrên Dîyar yên Nespesîfîk}

Di vê devokê de navdêrên dîyar yên ne spesîfîk, ji ber bandora tirkî tu carî netewîyane. Mesela,

Mînak: Hemû Axêver

\begin{tabular}{|l|l|l|l|l|l|l|}
\hline Em & $\begin{array}{l}\text { he } \\
r\end{array}$ & eydî-yê & da & mî/pez & jê & di-k-in \\
\hline \begin{tabular}{l|lll} 
1PJ.RS \\
T.
\end{tabular} & $\begin{array}{l}\text { he } \\
r\end{array}$ & $\begin{array}{l}\text { Ndr.- } \\
\text { TEW.Mê }\end{array}$ & $\begin{array}{l}\text { Daçe } \\
k\end{array}$ & $\begin{array}{l}\text { Ndr.RS } \\
\text { T. }\end{array}$ & $\begin{array}{l}\text { Daçe } \\
k\end{array}$ & Pêş.r.r.-kirin:k.d.n.-3PJ \\
\hline
\end{tabular}

Di vê mînakê de hemû axêver navdêra dîyar ya nespesîfîk "mî/pez" netewandine. Ev jî niş̧an dide ku navdêrên dîyar yên nespesîfîk di vê devokê de êdî nayê tewandin.

\subsubsection{Kișandina Navdêrên Nedîyar}

Di vê devokê de ji bilî axêverê mêr yê kal, tu axêver li hember zayendê hessesîyet nişan nedaye. Van axêveran yan tenê paşgira nedîyarîyê bi kar anîne yan jî forma nêr bi kar anîne. Mesela,

(1) (M.K.J.), (M.N.Mr.)

\begin{tabular}{|l|l|l|}
\hline Tu & pez-ek & di-doş-î \\
\hline 2YJ.RST. & Ndr(mê).-Paş.NeDyr. & Pêş.r.r.-dotin:k.d.n.-2YJ. \\
\hline
\end{tabular}

(2) (M.C.Mr.), (M.C.J.)

\begin{tabular}{|l|l|l|l|}
\hline Mêrkê & yaşlî & hemşîre-k-î & tîn-e. \\
\hline N.E.-îzf.Nêr & Rgd. & $\begin{array}{l}\text { Ndr(mê).-Paş.NeDyr.- } \\
\text { TEW.Nêr }\end{array}$ & Anîn:k.d.n.-3YJ. \\
\hline
\end{tabular}


Di mînaka ewil de navdêra mê "pez" divê bi \{-ek-ê\} ve bihata tewandin. Lê paşgira \{-ê\} ya ku zayenda navdêrê dide nehatîye bikaranîn. Dîsa di mînaka (2)yan de her çiqas navdêra "hemşîre" navdêreke mê be jî bi paşgira \{-î\}yê hatîye tewandin ku ev paşgir ji bo navdêrên nêr tê bikaranîn. Ev jî nîșan dide, di vê devokê de navdêr wextê bi awayekî nedîyar tên tewandin ji hêla zayendê ve hessesîyeta xwe winda dikin.

\subsubsection{Kișandina Cînavk û Rengdêrên Nîşanê}

Di vê devokê de ji bili axêverê mêr yê kal, hemû axêverên din li hember zayendê hessesîyetekê nîşan nedane. Navdêr wextê bi rengdêreke nîșanê ve tewîyaye, regdêrên nîşanê hem ji bo navdêrên nêr hem jî ji bo navdêrên mê wek nêr (vî, wî) û navdêr jî wek navdêrên mê bi \{-ê\} hatine tewandin. Mesela,

(1) Ji bilî (M.K.Mr.)ê hemû axêver

\begin{tabular}{|l|l|l|l|}
\hline Tu & Wî & mî-yê & di-doş-î \\
\hline 2YJ.RST. & Rgd.Nîş.Nêr & Ndr(mê).-TEW.Mê & $\begin{array}{l}\text { Pêş.r.r.-dotin:k.d.n.- } \\
\text { 2YJ. }\end{array}$ \\
\hline
\end{tabular}

(2) Ji bilî (M.K.Mr.)ê hemû axêver

\begin{tabular}{|l|l|l|l|}
\hline Em & wî & beran-ê & di-stîn-in \\
\hline 1PJ.RST. & Rgd.Nîş.Nêr & $\begin{array}{l}\text { Ndr(nêr).- } \\
\text { TEW.Mê }\end{array}$ & $\begin{array}{l}\text { Pêş.r.r.-standin:k.d.n.- } \\
\text { PJ. }\end{array}$ \\
\hline
\end{tabular}

(3) Ji bilî (M.K.Mr.)ê hemû axêver

\begin{tabular}{|l|l|l|l|}
\hline Ez & Wî & heval-ê & di-bîn-im \\
1YJ.RST. & Rgd.Nîş.Nêr. & $\begin{array}{l}\text { Ndr(cotzayend)- } \\
\text { TEW.Mê }\end{array}$ & $\begin{array}{l}\text { Pêș.r.r.-dîtin:k.d.n.- } \\
\text { 1YJ. }\end{array}$ \\
\hline
\end{tabular}

Di mînaka (1)î de navdêr mê, ya (2)yan de navdêr nêr û ya (3)yan de navdêr cotzayend e. Lê di hemûyan de rengdêra nîşanê nêr e û navdêr jî bi paşgira mê \{-ê\}yê ve hatiye kişandin. Dîsa di cînavkên nîşanê û cînavkên şexsî yên sêyem û yekjimar de jî navdêra ku refere lê tê kirin wek mê bê zanîn jî dîsa cînavka nîşanê û cînavka şexsî yê sêyem û yekjimar wek nêr (wî) tê bikaranîn. Dikare bê gotin ku di vê devokê de zayend di cînavk û rengdêrên nişanê de hema bêje ji holê rabûye.

Eger zayenda rewşa tewandî di vê devokê de di nav tabloyekê de bê dayîn wê wiha be; 
Di Devokên Kurdîya Kurmancî de Zayenda Rewşên Morfolojîk (Mînakên Devokên Bakur, Başûrê Rojhilat û Başûrê Rojavayê)

Tablo 4: Paşgirên Tewangê yên Di Devoka Bakur de

\begin{tabular}{|c|c|c|c|c|}
\hline & Dîyar & Dîyar Nespesîfîk & Nedîyar & $\begin{array}{c}\text { Cînavk û rengdêrên } \\
\text { Nîşanê }\end{array}$ \\
\hline Nêr & $\theta$ & \multirow{3}{*}{$\begin{array}{l}\text { Bi piranî bê paşgir } \\
\text { lê hin caran } \\
\text { paşgira pirjimarîyê }\end{array}$} & $\{-e k \hat{\imath}\}$ & vî.... $\{-\hat{e}\}$ \\
\hline Mê & $\{-\hat{e}\}$ & & $\{$-ekî\} & vî...\{-ê\} \\
\hline $\begin{array}{l}\text { Pirjim } \\
\text { ar }\end{array}$ & $\begin{array}{c}\{- \\
a(n)\}\end{array}$ & & hinek ... & $\operatorname{van} \ldots\{$-an $\}$ \\
\hline
\end{tabular}

Her wekî ji tabloyê jî tê dîtin di navdêrên dîyar de paşgira ji bo navdêrên nêr tê bikaranîn di vê devokê de nayê bikaranîn. Dîsa wextê navdêrên dîyar di rewşa nespesîfîk de têne kişandin, cihê ku paşgira tewangê bistînin, div ê devokê de paşgira tewangê nastînin. Wek dawî, di kişandina bi awayekî nedîyar û kişandina cînavk û rengdêrên nîşanê de di vê devokê de zayend bi temamî ji holê rabûye.

\subsubsection{Rewşa Bangkirinê}

Di rewşa bangkirinê de di vê devokê de navdêrên taybet tu paşgira zayendê nesitandine. Navdêrên cîns yên mê paşgira \{-ê\}yê standine. Wextê navdêr di vê rewşê de wek pirjimar hatine kişandin, herdu formên vê bikaranînê ji hêla axêveran ve hatine tercîhkirin. Hin ji wan berîya navdêrê bêjeya "ey" û pey navdêrê jî paşgira tewangê ya pirjimar \{-an\}ê bi kar anîne. Bi taybetî axêverên kal forma duyem yanê form ku paşgira $\{-(i)$ no\} li navdêrê zêde dibe bi kar anîne. 5

\subsection{Devoka Bașûrê Rojava}

Ji bo devoka başûrê Rojava bajarê Semsûrê hatîye hilbijartin. Axêver eslê xwe ji gundên nêz yên Semsûrê bûn lê wexteke dirêj e li navenda bajêr dijîn. Li vê derê bi şeş axêveran re hatîye axaftin. Analîza vê mintiqê li gor binbeşên zayenda rewşan wiha ye;

\subsubsection{Kișandina Navdêrên Dîyar}

Di vê devokê de navdêr wextê bi awayekî dîyar têne tewandin, navdêrên mê wek kurmancîya standart bi \{-ê\}yê têne tewandin û navdêrên nêr jî yan bi paşgira \{-î\}yê yan jî bi kişandina dengên /a/ an jî /e/ bo /ê/yê ve ditewin. Navdêrên

\footnotetext{
5 Her çiqas axêverên vê xebatê bi vî awayî bi kar anîbin jî devok xwedîyê bikaranînên din in jî. Hin caran rewş paşgirên zayendê di şûna hev de dikarin werin bikaranîn. Wek paşgira nêr \{-o\}ji bo navdêrên mê û paşira mê $\{$-ê\} ji bo navdêrên nêr. Mesela, ji "Siltan" re "Silto" ji "Ekrem" re "Ekê" tê gotin. Bi me ev di nav çarçoveya rewşa bangikirinê de divê neyê hesibandin. Dibe ku cihê derketina vê bikaranînê paşgirên bangkirinê bin lê ev halê tê bikaranîn ne rewşa bangkirinê ye. Lewa ji bo bangkirina kesan nayê bikaranîn.
} 
pirjimar jî bi $\{-a(n)\}$ ê ditewin. Navdêrên cotzayend pirî caran bê paşgir hatine bikaranîn.

(1) Hemû Axêver

\begin{tabular}{|l|l|l|l|}
\hline Ez & bûk- & -ê & du-wn-ime \\
\hline 1YJ.RST. & Ndr- & -TEW.Mê & Pêş.r.r.-dîtin:k.d.n-1YJ. \\
\hline
\end{tabular}

(2) (A.K.J.)

\begin{tabular}{|l|l|l|l|l|}
\hline Ew & $\hat{\imath}$ & zava- & -yî & di-wn-e \\
\hline 3YJ.RST. & Îzf.Brf. & Ndr.- & $\begin{array}{l}- \\
\text { TEW.Nê } \\
r\end{array}$ & $\begin{array}{l}\text { Pêş.r.r.-dîtin:k.d.n- } \\
\text { 3YJ. }\end{array}$ \\
\hline
\end{tabular}

(3) Ji bilî (A.C.J.) hemû axêver

\begin{tabular}{|l|l|l|l|}
\hline Em & ê & berên & di-kir-ine \\
\hline 1YJ.RST. & Îzf.Brf. & $\begin{array}{l}\text { Ndr.TEW.N } \\
\text { êr }\end{array}$ & Pêş.r.r.-kirîn:k.d.n.-PJ. \\
\hline
\end{tabular}

(4) (A.C.Mr.)

\begin{tabular}{|l|l|l|}
\hline Ez & heval & di-wn-ime \\
\hline 1YJ.RST. & Ndr.RST. & Pêş.r.r.-dîtin:k.d.n.-1YJ. \\
\hline
\end{tabular}

Mînaka (1)î ji bo tewandina navdêrên mê, ya (2) yan ji bo tewandina navdêrên nêr forma ewil ku paşgira \{-î\}yê bikar tîne û ya (3)yan jî ji bo navdêrên nêr forma duyem ku bi kişandina dengê /a/ bo dengê lê/yê mînak in. Mînaka (4)an ji bo nebûna tewangê ji bo navdêrên cotzayend e. Ev mînaka dawî ji hêla axêverê ciwan ve hatiye bikaranîn ev jî nîşan dide ku di zimanê ciwanan de tewang hêdî hêdî di rewşa dîyar de di navdêrên cotzayend de ji holê radibe.

\subsubsection{Kişandina Navdêrên Dîyar yên Nespesîfîk}

Di kişandina dîyar ya nespesîfîk de navdêrên ku dikarin bên jimartin wek yekjimar û yên ku nikarin bên jimartin jî wek pirjimar hatine bikaranîn. Axêvera ciwan ya jin di herdu rewşan de jî tu paşgirên tewangê bi kar neanîye. Mînak;

(1) Ji bilî (A.C.J.) hemû axêver

\begin{tabular}{|l|l|l|l|l|l|l|}
\hline Her & $\begin{array}{l}\text { qurba } \\
\mathrm{n}\end{array}$ & da & mi-yê & ser & jê & di-k-ine \\
\hline
\end{tabular}


Di Devokên Kurdîya Kurmancî de Zayenda Rewşên Morfolojîk (Mînakên Devokên Bakur, Başûrê Rojhilat û Başûrê Rojavayê)

\begin{tabular}{|l|l|l|l|l|l|l|}
\hline her & Ndr. & $\begin{array}{l}\text { daçe } \\
k\end{array}$ & $\begin{array}{l}\text { Ndr.- } \\
\text { TEW.Mê }\end{array}$ & Ndr. & daçek & Pêş.r.r.-kirin:k.d.n.-PJ. \\
\hline
\end{tabular}

(2) Ji bikî (A.K.J.) û (A.C.J.) hemû axêver

\begin{tabular}{|l|l|l|l|l|l|l|l|}
\hline Em & her & eydî & da & berên & ser & jê & di-k-ine \\
1PJ.RST. & her & Ndr. & $\begin{array}{l}\text { Daçe } \\
k\end{array}$ & $\begin{array}{l}\text { Ndr.TEW.Nê } \\
\text { r }\end{array}$ & $\begin{array}{l}\text { Nd } \\
\text { r. }\end{array}$ & $\begin{array}{l}\text { daçe } \\
k\end{array}$ & $\begin{array}{l}\text { Pêş.r.r.-kirin:k.d.n.- } \\
\text { PJ. }\end{array}$ \\
\hline
\end{tabular}

(3) Ji bilî (A.N.Mr) hemû axêver

\begin{tabular}{|l|l|l|l|l|l|}
\hline Ez & her & der-im & per-a & di-d-e & min \\
\hline 1YJ.RST. & her & $\begin{array}{l}\text { Çûyîn:k.d.n.- } \\
\text { 1YJ. }\end{array}$ & $\begin{array}{l}\text { Ndr.TEW. } \\
\text { PJ. }\end{array}$ & $\begin{array}{l}\text { Pêş.r.r.-dayîn:k.d.n.- } \\
\text { 3YJ. }\end{array}$ & 1YJ.TEW. \\
\hline
\end{tabular}

(4) (A.C.J.)

\begin{tabular}{|l|l|l|l|l|l|l|}
\hline Her & $\begin{array}{l}\text { qurba } \\
\mathrm{n}\end{array}$ & da & pez & ser & jê & di-k-ine \\
her & Ndr. & Daçek & Ndr.RST. & $\begin{array}{l}\text { Nd } \\
\text { r. }\end{array}$ & Daçek & Pêş.r.r.-kirin:k.d.n.-PJ. \\
\hline
\end{tabular}

(5) (A.N.Mr.)

\begin{tabular}{|l|l|l|l|l|}
\hline Her & der-im & pere & di-d-e & min \\
\hline her & Çûyîn:k.d.n.-1YJ. & Ndr.RST. & $\begin{array}{l}\text { Pêş.r.r.-dayîn:k.d.n.- } \\
\text { 3YJ. }\end{array}$ & 1YJ.TEW. \\
\hline
\end{tabular}

Di (1)î de navdêra mê ya "mî" ku wek dîyar û nespesîfîk hatî kişandin wek kurmancîya standart paşgira mê \{-ê\}yê standîye. Di (2)yan de jî navdêra nêr ya "beran" dîsa her çiqas nespesîfîk be jî wek nêr hatiye kişandin. Mînaka (3)yan ji bo navdêrên nayêne hejmartin mînak e. Di vê mînakê de navdêra nespesîfîk "pere" wek pirjimar hatîye kişandin. Mînakên (4) û (5)an ji bo bikaranînên axêverên ciwan mînak in. Di van mînakan de navdêrên nespesîfîk yên "pez" (4) û "pere" (5) bê paşgir hatine bikaranîn. Ev jî nîșan dide, di axêverên ciwan de bandora tirkî zêdetir e. Lewra ev bikaranîna bêpaşgir di encama bandora tirkî de pêk tê.

\subsubsection{Kișandina Navdêrên Nedîyar}

Di vê devokê de wextê navdêr bi awayekî nedîyar têne kişandin, wek kurmancîya standard têne kişandin. Lê paşgira nedîyarîyê \{-ek-\} bi ketina dengê 
le/yê ve dibe $\{-k-\}$. Navdêrên pirjimar jî wek kurmancîya standart paşgira \{(i)na(n)\} distîne. Dengê /n/yê pirî caran dikeve û hin caran jî dengê /i/yê dikeve. Mînak;

(1) Ji bilî (A.C.J.) hemû Axêver

\begin{tabular}{|l|l|l|}
\hline Ez & bûk-k-ê & di-wn-ime \\
\hline 1YJ.RST. & Ndr.-Paş.NeDyr.-TEW.Mê. & Pêş.r.r.-dîtin:k.d.n.-1YJ. \\
\hline
\end{tabular}

(2) Hemû Axêver

\begin{tabular}{|l|l|l|}
\hline Ez & çiya-k-î & di-wn-ime \\
\hline 1YJ.RST. & $\begin{array}{l}\text { Ndr.-Paş.NeDyr.- } \\
\text { TEW.Mê. }\end{array}$ & Pêş.r.r.-dîtin:k.d.n.-1YJ. \\
\hline
\end{tabular}

(3) Hemû Axêver

\begin{tabular}{|l|l|l|l|}
\hline Jinik & berxik-n-a & paç & di-k-e \\
\hline Ndr.RST. & Ndr.-Paş.NeDyr.-TEW.PJ. & Ndr. & Pêş.r.r.-kirin:k.d.n.-3YJ. \\
\hline
\end{tabular}

(4) (A.C.J.)

\begin{tabular}{|l|l|l|}
\hline Ez & gelin-k-î & di-wn-ime \\
\hline 1YJ.RST. & Ndr.(mê)-Paş.NeDyr.-TEW.Mê & Pêş.r.r.-dîtin:k.d.n.-1YJ. \\
\hline
\end{tabular}

Di (1)î de kişandina navdêrên mê bi awayekî nedîyar e. Di (2)yan de jî kişandina navdêrên mê bi awayekî nedîyar e. (3) jî ji bo kişandina pirjimar ya nedîyar mînak e. Di vê derê de paşgira $\{-(i) n a(n)\}$ hatiye bikaranîn. Mînaka (4)an ji bo çewt bikaranîna zayenda kişandina navdêrên nedîyar mînak e. Axêvera keçik ya jin lewra Kurmanciya wê baş nebû û bi bandora tirkî ve diaxivî, vê çewtiyê kirîye. Di vê derê de em dikarin behsa bandora tirkî bikin.

\subsubsection{Kișandina Cînavk û Rengdêrên Nîșanê}

Di vê devokê de bikaranîna cînavk û rengdêrên nîşanê wek kişandina kurmancîya standart e. Eger em bi mînakan bidin;

(1) Ji bilî (A.G.E.) hemû axêver

\begin{tabular}{|l|l|l|l|l|}
\hline Mêrik & $\hat{\imath}$ & vî & meraz-î & di-kir-e \\
\hline
\end{tabular}


Di Devokên Kurdîya Kurmancî de Zayenda Rewşên Morfolojîk (Mînakên Devokên Bakur, Başûrê Rojhilat û Başûrê Rojavayê)

\begin{tabular}{|l|l|l|l|l|}
\hline Ndr.RST. & Îzf.Brf. & Rgd.TEW.Nêr. & Ndr.-TEW.Nêr & $\begin{array}{l}\text { Pêş.r.r.-kirîn:k.d.n.- } \\
\text { 3YJ. }\end{array}$ \\
\hline
\end{tabular}

(2) (A.Y.K.)

\begin{tabular}{|l|l|l|l|l|l|}
\hline Jinik & ê & wê & telefon-ê & pere & di-kir-e \\
Ndr.RST. & Îzf.Brf. & $\begin{array}{l}\text { Rgd.TEW. } \\
\text { Mê }\end{array}$ & $\begin{array}{l}\text { Ndr.- } \\
\text { TEW.Mê }\end{array}$ & Ndr. & Pêş.r.r.-kirîn:k.d.n.-3YJ. \\
\hline
\end{tabular}

(3) Hemê Axêver

\begin{tabular}{|l|l|l|l|l|l|}
\hline Jinik & ê & va & berx-ina & paç & di-k-e \\
\hline Ndr.RST. & $\begin{array}{l}\text { Îzf.Br } \\
\text { f. }\end{array}$ & $\begin{array}{l}\text { Rgd.TEW. } \\
\text { PJ. }\end{array}$ & $\begin{array}{l}\text { Ndr.- } \\
\text { TEW.PJ }\end{array}$ & Ndr. & Pêş.r.r.-kirin:k.d.n.-3YJ. \\
\hline
\end{tabular}

(4) (A.K.J.)

\begin{tabular}{|l|l|l|l|}
\hline Ez & wê & heval-ê & di-wn-ime \\
\hline 1YJ.RST. & Rgd.TEW.Mê & Ndr.-TEW.Mê. & Pêş.r.r.-dîtin:k.d.n.-1YJ. \\
\hline
\end{tabular}

(1) ji bo kişandina navdêrên nêr bi regdêrên nîșanê mînak e. Dîsa mînaka (2)yan ji bo bikaranîna navdêrên mê ya bi rengdêra nîşanê re ye. Di (3)yan de navdêr wek pirjimar hatîye kişandin. Lê cihê $k u\{-a(n)\}$ bê bikaranîn navdêr paşgira $\{$-ina(n)\} standiye. Ev bikaranîn ne wek kurmancîya standart e. Di (4)an de mînak ji bo bikaranîna mê ji bo navdêrên cotzayend e. Rewşa normal de divê di çarçoveya nêrtîya gelenperî de divê navdêr û rengdêra nîşanê nêr bihata bikaranîn lê di vê derê de hem navdêr hem jî rengdêrên nîșanê mê hatîye kişandin. Sebebê vê jî zayenda biyolojik ya axêver e ku di vê mînakê de axêver jin.

Eger bikaranîna zayendê di rewşê de ji bo vê heremê di nav tabloyekê de bê dayîn wê wiha be;

Tablo 5: Paşgirên Tewangê yên Di Devoka Başûrê Rojava de

\begin{tabular}{|c|c|c|c|c|}
\hline \multirow{2}{*}{ Dîyar } & Dîyar Nespesîfîk & Nedîyar & $\begin{array}{c}\text { Cînavk û } \\
\text { Rengdêrên } \\
\text { Nîşanê }\end{array}$ \\
\hline Nêr & $\begin{array}{c}\{-\hat{i}\} / \text { an jî } \\
\text { kişandin }\end{array}$ & $\begin{array}{c}\text { Navdêrên tên hejmartin } \\
\text { yekjimar; navdêrên nayên }\end{array}$ & $(k)-\{-\hat{-1}\}$ & vî.... $\{-\hat{l}\}$ \\
\hline
\end{tabular}




\begin{tabular}{|c|c|c|c|c|}
\hline Mê & $\{-\hat{e}\}$ & $\begin{array}{c}\text { hejmartin wek pirjimar } \\
\text { têne kişandin. }\end{array}$ & $(k)-\{-\hat{e}\}$ & vê .... $\{-\hat{e}\}$ \\
Pirji & $\{-\mathrm{a}(\mathrm{n})\}$ & $\{-$ & $\mathrm{va}(\mathrm{n}) \ldots\{-$ \\
$\operatorname{mar}$ & & & $(\mathrm{i}) \mathrm{na}(\mathrm{n})\}$ & $(\mathrm{i}) \mathrm{na}(\mathrm{n})\}$ \\
\hline
\end{tabular}

Her wekî ji tabloyê jî tê xwîyanê bikaranîna zayenda tewanga ya di vê devokê de wek kurmancîya standart e. Tenê wextê navdêr bi rengdêrên nîșanê re bi awayekî pirjimar tê bikaranîn, cihê $k u\{-a(n)\}$ bê bikaranîn $\{-(i) n a(n)\}$ tê bikaranîn.

\subsubsection{Kişandina Rewşa Bangkirinê}

Di vê heremê de tu kes derveyî kurmancîya standart formeke din bikar neanîye. Yanê, di kurmancîya Standart de rewşa bangkininê çawa be, di vê devokê de jî wisa ye.

\section{Encam}

Di vê xebatê de ji mintiqeyên sê devokên kurdîya kurmancî yek cih hatiye hilbijartin û li ser wan devokan hatiye rawestan; devoka başûrê rojhilatê, devoka bakur û devoka başûrê rojavayê. Di van devokan de bikaranîna zayendê di rewşên morfolojîk de bi awayekî hûrgilî hate analîzkirin. Ji bo vê analîzê amûreke pîvandinê ji hêla nivîskarê vê gotarê ve hate pêşxistin û ev amûra pîvandinê ji bo van devokên hilbijartî hate tetbîqkirin. Çar bikararanînên cuda yên navdêran di rewşa tewandî de; dîyar, dîyar-nespesîfîk, nedîyar, cînavk û rengdêrên nîşanê û bikaranîneke navdêran di rewşa bangkirinê de bi hûrgilî hate tehlîlkirin.

Di serî de li ser tewanga navdêran bi awayekî dîyar hate rawestan. Di devoka başûrê rojhilat de tişta ku ji kurmancîya standart cuda ew bû ku,

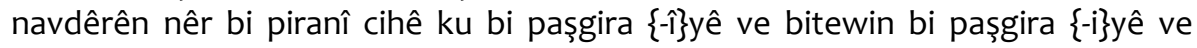
tewîyane. Di devoka başûrê rojava de, di vê kişandinê de forma kurmancîya standart hatiye bikaranîn. Di devoka bakur de jî tişta ji kurmancîya standart cuda dîsa bikaranîna navdêrên nêr de derdikeve pêşberî me. Di vê devokê de wextê navdêrên nêr ditewin tu paşgirê nastînin.

Her wekî li jor jî hate behskirin navdêrên dîyar dibe ku bi awayekî nespesîfîk bên bikaranîn. Di devoka başûrê rojhilat de, navdêrên dîyar yên nespesîfîk wek kurmancîya standart bi paşgirên yekjimariyê û pirjimariyê ve hatine kişandin. Lê di devoka bakur de navdêr wextê bi awayekî dîyar û nespesîfîk hatine kişandin, axêver ji ber bandora tirkî tu carî paşgirên tewangê bi kar neanîne. Di devoka başûrê rojava de, axêveran dîsa wek kurmancîya standart pey navdêrên dîyar yên nespesîfîk paşgiran bi kar anîne. 
Navdêr wextê di rewşa tewandî de bi awayekî nedîyar hatine kişandin; axêverên devoka başûrê rojhilat forma kurmancîya standart bi kar anîne. Lê navdêrên nêr cihê ku bi \{-(ek)î\}yê bên tewandin pirî caran bi \{-(ek)i\}yê hatine tewandin. Dîsa di vê devokê de ji bo navdêrên pirjimar ew form hatiye bikaranîn ku bêjeya "hinde"yê beriya navdêrê bi kar tîne. Di devoka bakur de navdêrên nedîyar wextê hatine kişandin hessesîyeta zayendê ji holê rabûye û hem navdêrên nêr hem jî navdêrên mê wek nêr bi paşgira \{-ekî\} ve hatine kişandin. Dîsa, di vê devokê de ji bo navdêrên pirjimar ew form hatiye bikaranîn ku bêjeya "hinek"ê beriya navdêrê bi kar tîne. Di devoka başûrê rojava de dîsa forma di kurmancîya standart de heyî hatiye bikaranîn. Lê paşgira \{-ek-\} bê dendê /e/yê wek $\{-k-\}$ hatiye bikaranîn. Di pirjimaran de jî ew form hatîye bikaranîn ku navdêr paşgira $\{-(\mathrm{i}) \mathrm{na}(\mathrm{n})\}$ distîne.

Wek dawî ji bo zayenda di tewangê de li ser bikaranîna cînavk û rengdêrên nîşanê hatîye sekinîn. Axêverên devoka başûrê rojhilat, dîsa forma kurmancîya standart bi kar anîye. Lê her wekî çawa di rewşa dîyar û nedîyar de di kişandina navdêrên nêr de cihê $\{-1\}$ yê de denge $\{-i\} y e ̂$ hatîye bikaranîn, di vê derê de jî dîsa hem /î/ya rengdêrên nîșanê $\{-v /$ wî\}yê hem jî $\{-1$ \}ya tê navdêr û navdêr ditewîne pirî caran wek $\{-i\}$ hatîye bikaranîn. Di devoka bakur de, rengdêrên nîșanê û navdêrên bi wan re tên tewandin hessesîyeta xwe ya li hember zayendê wunda kirine. Rengdêrên nîșanê, cînavkên nîşanê û cînavkên kesî yên şexsên sêyem yên yekjimar di zayenda nêr yanê (v/wî) de standardîze bûne û paşgirên tewangê yên bi cînavkên nîşanê re hatî bikaranîn jî di paşgira mê $\{-\hat{e}\}$ de standardîze bûne. Di devoka başûrê rojava de, cînavk û rengdêrên nîşanê di yekjimaran de wek kurmancîya Standart hatine bikaranîn. Di pirjimaran de wextê navdêr bi regdêrên nîşanê re hatine bikaranîn, cihê $k u\{-a(n)\}$ bistînin wek nedîyaran $\{-(i) n a(n)\}$ standine.

Ji bo kişandina rewşa bangkirinê ev dikare bê gotin ku hemû devokan de kêm zêde hessesîyet li hember zayendê heye. Lê di devoka başûrê rojhilat de di navdêrên taybet de pirî caran paşgirên zayendê nehatine bikaranîn û dîsa di devoka bakur de tenê axêverên kal hessesîyet li hember zayendê nîşan dane.

Em dikarin wek dawî ji bo bikaranîna zayenda rewşan di sê devokên kurmancî de vê bêjin; devokên başûrê rojhilat û başûrê rojava di hemû kişandina de li hember zayendê hessasîyet nîșan dane. Lê devoka bakur di navdêrên dîyar de navdêrên nêr bê paşgir hîştine. Dîsa di navdêrên dîyar yên ne spesîfîk de ji ber bandora tirkî cihê ku axêver paşgiran bi kar bînin, paşgiran bi kar neanîne. Di navdêrên bi awayekî nedîyar hatî kişandin û navdêrên bi rengdêrên nîșanê re hatine bikaranîn de hessesîyeta zayendê hunda bûye. Wek dawî ev jî divê bê gotin ku, axêferên ciwan bi piranî xeletiyên zayendê kirine. Sebebê vê jî bi me bandora tirkî û nezanîna kurmancî ya bi awekî rêk û pêk e.

Ji bo xebatên bê, amûra pîvandinê ya vê xebatê dikare ji bo devokên din bê tetbîqkirin û bi vê awayî cudahî û guherînîn zayenda rewşan dikare bi vê awayî hem di devokên kurmancî de hem jî di navbera axêferan de bê teqîbkirin. 


\section{Çavkanî}

Adak, A. Aydın. T. Ergün. Z. û Bülbül. M. (2016). Fêrkera Kurdî (Asta Destpêkê). Mardin: Mardin Artuklu Üniversitesi Yayınları.

Akin, S. (2005). Têkçûna Zayendê di Zaravayê kurmancî de. Di nav Gotarên Konferansa li ser Zimanê Kurdî. Îstanbul: Weşanên Enstituya Kurdî ya Stenbolê.

Aksan, D. (2015). Her Yönüyle Dil (Ana çizgileriyle Dilbilim) II Cilt. Ankara: Türk Dil Kurumu Yayınları.

Bedir Han, C. \& Lescot, R. (2004). Kürtçe Gramer. (Paris Kürt Enstitüsü Gözetiminde Türkçeye Çevirilmiştir) İstanbul: Avesta Yayınları.

Corbett, G. (1991). Gender. Cambridge: Cambridge University Press.

Ekici. D. (2007). Kurmanji Kurdish Reader. Hyattsville, USA: Dunwoody Press.

Haig, G. (2000). The Gender System in the Kurdish Language: Structural and Sociolinguistic Aspects. Li ser Kurdish Gender Studies li Katzow û ji muswedda di navbera dîroka 23-25.09.2000 de hatî kirin. Em makale bi Almanî bi vî awayî derketîye; Haig, G. (2004). Das Genussystem in der kurdischen Sprache: strukturelle und soziolinguistische Aspekte. Hajo, S. Borck, C., Savelsberg, E. \& D. Şukriye (Ed.). Di nav Gender in Kurdistan und der Diaspora (33-58). Münster: Lit.

Haig, G. \& Öpengin, E. (2014a). Gender in Kurdish: Structural and Socio-cultural Dimentions. Hellinger, M. \& H. Motschenbacher (Ed.). Din av Gender Across Languages Sayı. IV, (247-276). John Benjamin.

(2014b). Regional Variation in Kurmanji: A Preliminary

Classification of Dialects. Di nav The Journal of Kurdish Studies S. 2, No. 2, (143-176).

İssever, S. (2006). Türkçede Takısız Nesne Adöbekleri ve Çalkalama. Di nav Ankara Üniversitesi Dil Dergisi (sayı:131) (42-55). Ankara: Ankara Üniversitesi TÖMER.

Komxebata Kurmancîyê. (2016). Rêbera Rastnivîsînê. Dîyarbekir: Weqfa Mezopotamyayê.

MacKenzie, D.N. (1954). Gender in Kurdish. Di nav Bulletin of the School of Oriental and African Studies 16/3 (528-541). London: University of London.

Öpengin, E. (2011). Rewşa Kurdî ya Sosyolenguîstîk li Tirkiyeyê. İstanbul: Avesta Yayınları.

Samûr, A. (2012). Kurdîya Kurmancî. Stenbol: Nûbihar.

Tan, S. (2015). Rêzimana Kurmancî. (3.Baskı). Stenbol: Weşanên Enstîtuya Kurdî ya Stenbolê.

Taş, Ç. (2013). Waneyên Rêziman û Rastnivîsa Kurmancî. İstanbul: Weşanên Dîwanê.

Yonat, M. "Notên Dersa Destpêka Morfolojîya Kurdî".

Zinar, Z. (2009). Di Çanda Kurdi de 37 Şaxên Zanistê. Stockholm: Weşanên Pêncinarê. 
Di Devokên Kurdîya Kurmancî de Zayenda Rewşên Morfolojîk (Mînakên Devokên Bakur, Başûrê Rojhilat û Başûrê Rojavayê)

\section{PÊVEK}

\section{Kurtebêjeyên Gotarê}

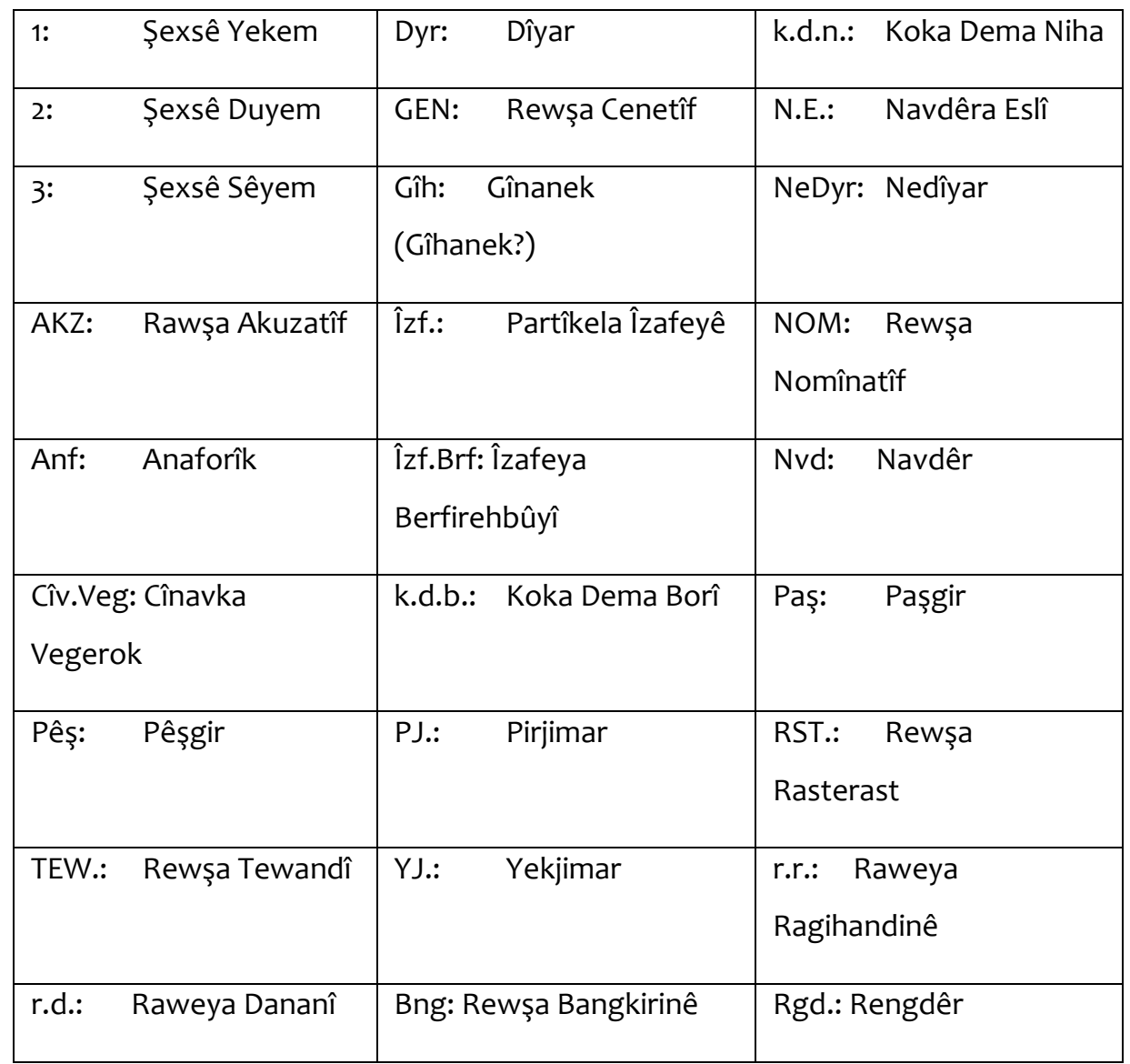


Pêvek 1: Rewșa Tewandî

\subsection{Kişandina Dîyar}

\begin{tabular}{|c|c|c|}
\hline Însan, merivantî, mê & Ez bûkê dibînim & Ben gelini görüyorum. \\
\hline Ne-însan, mê & Tu mihê didoşî & Sen koyunu sağıyorsun. \\
\hline Însan, merivantî, nêr & Ew zavayî dibîne & O damadı görüyor. \\
\hline Ne-însan, nêr & Em beranî dikirin & Biz koçu satın alıyoruz. \\
\hline Nejîndar, nêr & Hun çiyayî dibînin? & $\begin{array}{l}\text { Siz dağı görüyor } \\
\text { musunuz?. }\end{array}$ \\
\hline Nejîndar, mê & Ew darê dişkênin & Onlar ağacı kırıyorlar. \\
\hline Însan, mê, qerzkirî & $\begin{array}{l}\text { Mêrikê kal hemşîreyê } \\
\text { tîne. }\end{array}$ & $\begin{array}{l}\text { Yaşlı adam hemşireyi } \\
\text { getiriyor. }\end{array}$ \\
\hline Însan, nêr, qerzkirî & $\begin{array}{l}\text { Gundiyên Muşê } \\
\text { cendirmeyî têr dikin }\end{array}$ & $\begin{array}{l}\text { Muş’un köylüleri } \\
\text { jandarmayı doyuruyorlar. }\end{array}$ \\
\hline Qerzkirî, îcadkirî & Jinik telefonê dikire & $\begin{array}{l}\text { Kadın telefonu satın } \\
\text { alıyor. }\end{array}$ \\
\hline $\begin{array}{l}\text { Qerzkirî, yên bêjeyekê ji } \\
\text { bo wê di kurmancî de } \\
\text { heyî }\end{array}$ & Mêrik yaxî dixe erebê & $\begin{array}{l}\text { Adam arabaya yağı } \\
\text { koyuyor }\end{array}$ \\
\hline $\begin{array}{l}\text { Pirjimar, yên tên } \\
\text { hejmartin }\end{array}$ & $\begin{array}{l}\text { Jinika rind berxan maç } \\
\text { dike }\end{array}$ & $\begin{array}{l}\text { Guzel kadın kuzuları } \\
\text { öpüyor }\end{array}$ \\
\hline $\begin{array}{l}\text { Pirjimar, Yên nayên } \\
\text { hejmartin }\end{array}$ & Qehwecî çayan tijî dike & $\begin{array}{l}\text { Kahveci } \\
\text { dolduruyor }\end{array}$ \\
\hline Pirjimar+pirjimar & Şivanê ciwan çêlek û & Genç çoban inek ve \\
\hline
\end{tabular}


Di Devokên Kurdîya Kurmancî de Zayenda Rewşên Morfolojîk (Mînakên Devokên Bakur, Başûrê Rojhilat û Başûrê Rojavayê)

\begin{tabular}{|l|l|l|}
\hline & conegeyan diçêrîne. & boğaları otlatıyor. \\
\hline Cotzayend & Ez hevalî/ê dibînim & Ben arkadaşı görüyorum \\
\hline Cînavkê sêyemê yekjimar & Ez wî/wê dibînim & Onu görüyorum \\
\hline
\end{tabular}


1.2. Kișandina Dîyar ya Nespesîfîk

\begin{tabular}{|l|l|l|}
\hline $\begin{array}{l}\text { Jîndar, mê, yên tên } \\
\text { hejmartin, nespesîfîk }\end{array}$ & $\begin{array}{l}\text { Em di her qurbanê de } \\
\text { mihekê/mihan ser jê dikin }\end{array}$ & $\begin{array}{l}\text { Biz her bayramda } \\
\text { koyun keseriz }\end{array}$ \\
\hline $\begin{array}{l}\text { Jîndar, mê, yên tên } \\
\text { hejmartin, nespesîfîk }\end{array}$ & $\begin{array}{l}\text { Em di her qurbanê de } \\
\text { beranekî/beranan ser jê } \\
\text { dikin }\end{array}$ & $\begin{array}{l}\text { Biz her beseriz bayramda } \\
\text { koç kes }\end{array}$ \\
$\begin{array}{l}\text { Nejîndar, nêr, yên têne } \\
\text { hejmartin, nespesîfîk }\end{array}$ & $\begin{array}{l}\text { Çiqas ez diçim, pereyan dide } \\
\text { min }\end{array}$ & $\begin{array}{l}\text { Her gidişimde bana } \\
\text { para verir }\end{array}$ \\
$\begin{array}{l}\text { Nejîndar, mê, yên } \\
\text { nayêne hejmartin, çiqas diçim, ew çayekê } \\
\text { nespesîfîk }\end{array}$ & $\begin{array}{l}\text { dide min } \\
\text { çay verir }\end{array}$ \\
\hline
\end{tabular}


Di Devokên Kurdîya Kurmancî de Zayenda Rewşên Morfolojîk (Mînakên Devokên Bakur, Başûrê Rojhilat û Başûrê Rojavayê)

\subsection{Kișandina Nedîyar}

\begin{tabular}{|c|c|c|}
\hline Însan, merivantî, mê & Ez bûkekê dibînim & Ben bir gelin görüyorum. \\
\hline Ne-însan, mê & Tu mihekê didoşî & $\begin{array}{l}\text { Sen bir koyun } \\
\text { sağıyorsun. }\end{array}$ \\
\hline Însan, merivantî, nêr & Ew zavayekî dibîne & O bir damat görüyor. \\
\hline Ne-însan, nêr & Em beranekî dikirin & Biz bir koç satın alıyoruz. \\
\hline Nejîndar, nêr & Hun çiyayekî dibînin & $\begin{array}{l}\text { Siz bir dağ } \\
\text { görüyorsunuz. }\end{array}$ \\
\hline Nejîndar, mê & Ew darekê dişkênin & Onlar bir ağaç kırıyorlar. \\
\hline Însan, mê, qerzkirî & $\begin{array}{l}\text { Mêrikê kal hemşîreyekê } \\
\text { tîne. }\end{array}$ & $\begin{array}{l}\text { Yaşlı adam bir hemşire } \\
\text { getiriyor. }\end{array}$ \\
\hline Însan, nêr, qerzkirî & $\begin{array}{l}\text { Gundiyên Mûşê } \\
\text { cendirmeyekî têr dikin }\end{array}$ & $\begin{array}{l}\text { Muş'un köylüleri bir } \\
\text { jandarma doyuruyorlar. }\end{array}$ \\
\hline Qerzkirî, îcadkirî & Jinik telefonekê dikire & $\begin{array}{l}\text { Kadın bir telefon satın } \\
\text { alıyor. }\end{array}$ \\
\hline $\begin{array}{l}\text { Qerzkirî, yên bêjeyekê ji } \\
\text { bo wê di kurmancî de } \\
\text { heyî }\end{array}$ & Mêrik eyeqabîyekî dikire & $\begin{array}{l}\text { Adam bir ayakkabı satın } \\
\text { alıyor. }\end{array}$ \\
\hline $\begin{array}{l}\text { Pirjimar, yên tên } \\
\text { hejmartin }\end{array}$ & $\begin{array}{l}\text { Jinika rind hin berxan } \\
\text { maç dike }\end{array}$ & $\begin{array}{l}\text { Guzel kadın bazı kuzuları } \\
\text { öpüyor }\end{array}$ \\
\hline $\begin{array}{l}\text { Pirjimar, Yên nayên } \\
\text { hejmartin }\end{array}$ & $\begin{array}{l}\text { Qehweci hin çayan tijî } \\
\text { dike }\end{array}$ & $\begin{array}{l}\text { Kahveci bazı çayları } \\
\text { dolduruyor. }\end{array}$ \\
\hline Pirjimar+pirjimar & Şivanê ciwan hin çêlek û & Genç çoban bazı inek ve \\
\hline
\end{tabular}




\begin{tabular}{|l|l|l|}
\hline & conegeyan diçêrîne. & boğaları otlatıyor \\
Cotzayend & Ez hevalekî dibînim & $\begin{array}{l}\text { Ben bir arkadaşı } \\
\text { görüyorum }\end{array}$ \\
\hline $\begin{array}{l}\text { Cînavkê } \\
\text { yekjimar }\end{array}$ & Sêyemê yekî dibînim & Ben birini görüyorum \\
\hline
\end{tabular}


Di Devokên Kurdîya Kurmancî de Zayenda Rewşên Morfolojîk (Mînakên Devokên Bakur, Başûrê Rojhilat û Başûrê Rojavayê)

\subsection{Kişandina Cînavk û Rengdêrên Nîșanê}

\begin{tabular}{|c|c|c|}
\hline Însan, merivantî, mê & Ez vê bûkê dibînim & $\begin{array}{l}\text { Ben bu gelini } \\
\text { görüyorum. }\end{array}$ \\
\hline Ne-însan, mê & Tu wê mihê didoşî & $\begin{array}{l}\text { Sen } \quad 0 \quad \text { koyunu } \\
\text { sağıyorsun. }\end{array}$ \\
\hline Însan, merivantî, nêr & Ew vî zavayî dibîne & O bu damadı görüyor. \\
\hline Ne-însan, nêr & Em wî beranî dikirin & Biz o koçu satın alıyoruz. \\
\hline Nejîndar, nêr & Hun wî çiyayî dibînin & Siz o dağı görüyorsunuz. \\
\hline Nejîndar, mê & Ew vê darê dişkênin & Onlar bu ağacı kırıyorlar. \\
\hline Însan, mê, qerzkirî & $\begin{array}{l}\text { Mêrikê kal wê hemşîreyê } \\
\text { tîne. }\end{array}$ & $\begin{array}{l}\text { Yaşlı adam o hemşireyi } \\
\text { getiriyor. }\end{array}$ \\
\hline Însan, nêr, qerzkirî & $\begin{array}{l}\text { Gundiyên } \quad \text { Mûşê } \quad \text { vî } \\
\text { cendirmeyî têr dikin }\end{array}$ & $\begin{array}{l}\text { Muş'un köylüleri bu } \\
\text { jandarmayı doyuruyorlar. }\end{array}$ \\
\hline Qerzkirî, îcadkirî & Jinik wê telefonê dikire & $\begin{array}{l}\text { Kadın o telefonu satın } \\
\text { alıyor. }\end{array}$ \\
\hline $\begin{array}{l}\text { Qerzkirî, yên bêjeyekê ji } \\
\text { bo wê di kurmancî de } \\
\text { heyî }\end{array}$ & Mêrik vî eyeqabîyî dikire & $\begin{array}{l}\text { Adam bu ayakkabı satın } \\
\text { alıyor. }\end{array}$ \\
\hline $\begin{array}{l}\text { Pirjimar, yên tên } \\
\text { hejmartin }\end{array}$ & $\begin{array}{l}\text { Jinika rind van berxan } \\
\text { maç dike }\end{array}$ & $\begin{array}{l}\text { Guzel kadın bu kuzuları } \\
\text { öpüyor }\end{array}$ \\
\hline $\begin{array}{l}\text { Pirjimar, Yên nayên } \\
\text { hejmartin }\end{array}$ & $\begin{array}{l}\text { Qehweci wan çayan tijî } \\
\text { dike }\end{array}$ & $\begin{array}{l}\text { Kahveci o çayları } \\
\text { dolduruyor. }\end{array}$ \\
\hline Pirjimar+pirjimar & Şivanê ciwan wan çêlek & Genç çoban o inek ve \\
\hline
\end{tabular}




\begin{tabular}{|c|c|c|}
\hline & û conegeyan diçêrîne. & boğaları otlatıyor \\
\hline Cotzayend & Ez wî/ê hevalî/ê dibînim & $\begin{array}{l}\text { Ben } \quad 0 \quad \text { arkadaşı } \\
\text { görüyorum }\end{array}$ \\
\hline $\begin{array}{l}\text { Cînavkê sêyemê } \\
\text { yekjimar }\end{array}$ & Ez wî/wê dibînim & Ben onu görüyorum \\
\hline
\end{tabular}


Di Devokên Kurdîya Kurmancî de Zayenda Rewşên Morfolojîk (Mînakên Devokên Bakur, Bașûrê Rojhilat û Başûrê Rojavayê)

\subsection{Kişandina Rewşa Bangkirinê}

\begin{tabular}{|l|l|l|}
\hline $\begin{array}{l}\text { Yekjimar, mê, navdêrên } \\
\text { taybet }\end{array}$ & Sînemê! & Ey Sinem! \\
\hline $\begin{array}{l}\text { Yekjimar, nêr, navdêrên } \\
\text { taybet }\end{array}$ & Kenano! & Ey Kenan! \\
\hline $\begin{array}{l}\text { Yekjimar, mê, navdêrên } \\
\text { Cîns }\end{array}$ & Bûkê! & Ey gelin! \\
\hline $\begin{array}{l}\text { Yekjimar, mêr, navdêrên } \\
\text { Cîns }\end{array}$ & Camêro! & Ey Delikanlı! \\
\hline Pirjimar, Nêr & Camêrno! (Plural + Male) & Ey delikanlılar! \\
\hline Pirjimar, Mê & Caniknê! (Plural + & Ey genç kızlar! \\
\hline
\end{tabular}

